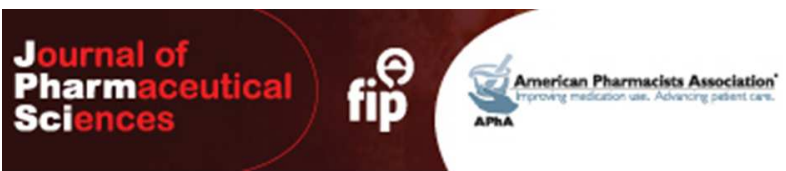

\title{
The repurposing of ivermectin for malaria: a prospective pharmacokinetics-based virtual clinical trials assessment of dosing regimen options
}

\begin{tabular}{|r|l|}
\hline Journal: & Journal of Pharmaceutical Sciences \\
\hline Manuscript ID & 18-018.R1 \\
\hline Article Type: & Research Article \\
\hline Date Submitted by the Author: & n/a \\
\hline Complete List of Authors: & $\begin{array}{l}\text { Badhan, Raj; Aston University, School of Pharmacy, Life \& Health Sciences } \\
\text { Zakaria, Zaril; Aston University, School of Pharmacy, Life \& Health } \\
\text { Sciences; Ministry Of Health Malaysia, , Block E1, E3, E6, E7 \& E10, Parcel } \\
\text { E, Federal Government Administration Centre } \\
\text { Olafuyi, Olusola; Aston University, School of Pharmacy, Life \& Health } \\
\text { Sciences }\end{array}$ \\
\hline Keywords: & $\begin{array}{l}\text { Physiologically based pharmacokinetic modeling, Pharmacokinetics, Drug } \\
\text { resistance, Onychomycosis, In silico modeling }\end{array}$ \\
\hline &
\end{tabular}


1 The repurposing of ivermectin for malaria: a prospective pharmacokinetics-based

2 virtual clinical trials assessment of dosing regimen options

3

4

$5 \quad$ Raj Badhan ${ }^{1}$, Zaril Zakaria $^{2,3}$ and Olusola Olafuyi ${ }^{3}$

6

$7{ }^{1}$ Applied Health Research Group, Aston Pharmacy School, Aston University, Birmingham, 8 B4 7ET, United Kingdom.

$9 \quad{ }^{2}$ Ministry Of Health Malaysia, Block E1, E3, E6, E7 \& E10, Parcel E, Federal Government

10 Administration Centre, 62590, Putrajaya, Malaysia

$11{ }^{3}$ Aston Pharmacy School, Aston University, Birmingham, B4 7ET, United Kingdom.

14 Correspondence:

15 Dr Raj Badhan

16 Aston Pharmacy School

17 Life and Health Sciences

18 Aston University

19 Birmingham

20 B4 7ET

21 UK

22 Telephone: +441212043288

23 E-mail: r.k.s.badhan@aston.ac.uk 


\begin{abstract}
25 ABSTRACT
26 Ivermectin has demonstrated many successes in the treatment of a range of nematode 27 infections. Considering the increase in malaria resistance attention has turned towards 28 ivermectin as a candidate for repurposing for malaria. This study developed and validated an 29 ivermectin physiologically-based pharmacokinetic model in healthy adults (20-50 years) and 30 paediatric (3-5 years $/ 15-25 \mathrm{~kg}$ ) subjects and in a representative adult malaria population 31 group (Thailand). Dosing optimisation demonstrated a twice daily for 3- or 5-day regimens 32 would provide a time above the LC50 of more than 7 days for adult and paediatric. 33 Furthermore, to address the occurrence of CYP450-induction often encountered with 34 antiretroviral agents, simulated drug-drug interaction studies with efavirenz highlighted that a $351 \mathrm{mg} / \mathrm{kg}$ once daily dose for five days would counteract the increased ivermectin hepatic 36 clearance and enable a time above LC50 of 138.8 hours in adults and 141.2 hours in 37 paediatric subjects.

38 It was also demonstrated that dosage regimen design would require consideration of the age39 weight geographical relationship of the subjects, with a dosage regimen for a representative 40 Thailand population group requiring at least a single daily dose for 5 days to maintain 41 ivermectin plasma concentrations and a time above LC50 similar to that in healthy adults.
\end{abstract}




\section{KEYWORDS}

44 Physiologically-based pharmacokinetics; pharmacokinetics; drug resistance; Onychomycosis;

45 in-silico modelling. 


\section{1. INTRODUCTION}

47 In May 2015, the World Health Organisation published a future strategy for tackling malaria, 48 the 'Global Technical Strategy for Malaria 2016-2030', which highlighted the need for 49 continued work towards tackling the significant risks many of the world's population face 50 with malaria infection. It has been estimated that 3.2 billion people are at risk of malaria with 51 up to 283 million cases of diagnosed malaria worldwide in 2013. Despite a global decline in 52 malaria mortality rates, there still remain challenges in many regions, particularly within sub53 Saharan Africa, where the greatest level of mortality is evident ${ }^{1}$. Where effective drug 54 treatments are available, the mortality that is associated with treatments for falciparum 55 malaria is $<0.1 \%{ }^{2}$. However, where the parasite is able to multiply untamed, the parasite 56 burden of the host increases resulting in organ dysfunction, impairment of higher brain 57 function, loss of consciousness and anaemia, culminating in death.

58 A major shift in treatment strategies for malaria may be required, considering the increasing 59 prevalence of anti-microbial resistance which has been exemplified by the emergence of 60 resistance to chloroquine ${ }^{3}$ and sulfadoxine/pyrimethamine (SP) ${ }^{4,5}$. Furthermore, the 61 appearance of an artemisinin drug-resistance strain of malaria within the Greater Mekong 62 Subregion (GMS), first identified in Cambodia in $2008^{6}$, poses particular concerns and 63 demonstrates the need to explore alternative antimalarial agents. This is further highlighted 64 by the increasing treatment failure associated with mefloquine and piperaquine across the 65 GMS $^{7-10}$.

66 The 'Global Technical Strategy for Malaria' ${ }^{1}$ comments on novel approaches required to aid 67 malaria treatment and specifically focuses on opportunities for 'innovation in medicines', 68 which provides a framework for the acceleration of malaria elimination. Given the 69 complexity of current drug discovery and development strategies, consideration of existing, 70 clinically approved, candidate molecules with a view to repurposing for malaria has many 71 advantages. For example, the safety profile and clinical pharmacokinetics would have been 72 established, and fast-track processes (e.g. FDA) allow for the establishment of new clinical 73 indications ${ }^{11}$. Such approaches have found successes in the area of orphan diseases ${ }^{12}$, where 74 specific unmet need exists and where traditional drug development strategies would be time75 consuming. Ivermectin, is one potential candidate that may be suited for repurposing to 76 malaria. Ivermectin is an endectocide and kills a range of parasites and associated vectors, 77 and is currently marketed and licenced to treat onchocerciasis, lymphatic filariasis, 
strongyloidiasis, scabies and head lice ${ }^{13}$. The use of ivermectin in the treatment of onchocerciasis has been well documented over the past 25 years with community-wide mass drug administration (MDA) of ivermectin contributing to the near elimination of onchocerciasis ${ }^{14}$. Further, numerous studies have demonstrated that ivermectin can remain in the blood stream for a sufficiently long time-frame, following standard dosing, to kill the Anopheline vector ${ }^{15-19}$ and malaria parasite ${ }^{20}$.

The importance of ivermectin as a potential novel drug for repurposing to malaria is exemplified by the formation of the 'Ivermectin Research for Malaria Elimination Network' ${ }^{21}$, whose primary goal was to establish a common research agenda to aid in the generation of evidence base on which to support (or otherwise) whether ivermectin should be repurposed to malaria. Further we strongly recommend those wishing to gain an in-depth understanding of the repurposing ivermectin to consider a recent series of reviews exploring the pharmacokinetics evidence, regulatory policies and clinical development pathways to support the repurposing of ivermectin to malaria ${ }^{22-24}$

Ivermectin shows rapid absorption with an absorption half-life of $0.5-2.5$ hours ${ }^{25,26}$, is highly lipophilic and is associated with extensive protein binding $(\mathrm{fu}<0.1)$ and a large volume of distribution $(3.1-3.5 \mathrm{~L} / \mathrm{kg})^{25}$. The metabolism of ivermectin is primarily mediated by Cytochrome P450 3A4 (CYP3A4) ${ }^{27}$ and leads to a half-life of approximately 18 hours ${ }^{25}$. A complete description of the pharmacokinetics of ivermectin can be found in two review publications ${ }^{22,25}$.In clinical studies, ivermectin has been used across an extensive dosing range, with over 2.7 billion single doses of the $0.15-0.2 \mathrm{mg} / \mathrm{kg}$ dose administered through the Mectizan Donation program ${ }^{28}$ as single doses. Furthermore, higher doses of up to $2 \mathrm{mg} / \mathrm{kg}$ as single doses have been administered ${ }^{29}$ whilst the Centre for Disease Control and Prevention have recommended doses of up to $1.4 \mathrm{mg} / \mathrm{kg}$ for severe crusted scabies ${ }^{30}$. The wide safety profile would suggest higher doses are well tolerated. However, there are no current clinical trials assessing possible dosing regimens that could be used to identify an appropriate treatment regimen for use in malaria. A recent report has identified the ivermectin concentration capable of killing $50 \%$ (LC50) mosquitoes as being approximately $16 \mathrm{ng} / \mathrm{mL}^{31}$, which could be used as a first-principle potential target concentration for 'therapeutic-effect'.

This manuscript, therefore, attempts to pragmatically assess the impact of possible dosing regimen designs on ivermectin plasma concentrations, with an emphasis on maintaining 
110 plasma concentration above the LC50, through the application of physiologically-based

111 pharmacokinetic (PBPK) modelling using virtual clinical trials.

112 The key objectives were therefore to: (i) assess the impact of dose escalation of ivermectin on 113 adults (20-50 years old) and paediatrics within the age range of 3-5 years old, who pose 114 significant challenges in treatment and are prone to developing severe malaria ${ }^{1}$; (ii) given 115 that ivermectin is metabolised by CYP3A4, to assess the impact of induction based drug-drug 116 interactions (DDIs) on reducing ivermectin plasma concentrations in adults and children and 117 (iii) to illustrate the potential changes in ivermectin pharmacokinetics when dosed to a 118 representative malaria population group originating from the GMS (i.e. Thailand).

119

120

121

122

123

124

125

126

127

128

129

130

131

132

133

134

135

136

137

138

139

140

\section{METHODS}

All population based PBPK modelling was conducted using the virtual clinical trials simulator Simcyp (Simcyp Ltd, a Certara company, Sheffield, UK, Version 16). Unless otherwise stated, mixed gender (50:50) populations were simulated. A six-stage workflow approach was applied for the development, validation and simulation of the ivermectin (Figure 1). The default Simcyp validated adult and paediatric 'healthy volunteer' population groups were used in simulations for Steps 1-5. The latter population group accounted for ontogenic related changes in physiological/biochemical parameters such as organ volumes, organ perfusion and drug metabolising enzymes ${ }^{32-34}$. Further, the Simcyp population groups account for population variability through the inclusion of a variability metric (\% coefficient variability) which was established from public health data bases such as the US National health and Nutrition Examination Survey (https://www.cdc.gov/nchs/nhanes/).

\subsection{Step 1: Base model development and validation}

A full description of the model development can be found in Section 1 of the Supplementary Materials. For model development, clinical studies selected included: (i) single doses (30, 60,90 and $120 \mathrm{mg}$ ) and multiple doses (30 $\mathrm{mg}$ and $60 \mathrm{mg}$ daily for 7 days) in healthy subjects ${ }^{29}$; (ii) a single (tablet) $12 \mathrm{mg}$ dose administered to healthy subjects ${ }^{35}$; (iii) a single $0.15 \mathrm{mg} / \mathrm{kg}$ dose administered to healthy subjects ${ }^{36}$; (iv) a single $0.20 \mathrm{mg} / \mathrm{kg}$ dose administered to healthy subjects ${ }^{37}$; a single $0.15 \mathrm{mg} / \mathrm{kg}$ dose administered to healthy subjects ${ }^{38}$; (v) single $0.15 \mathrm{mg} / \mathrm{kg}$ dose administered to onchocerciasis subjects ${ }^{39}$. A recent study by Ouédraogo et al. $2015^{40}$ provided some additional ivermectin plasma concentration data, but this was excluded from the validation approaches due to the sparse nature of the data and the 
141 lack of quantitative summary pharmacokinetics data (e.g $C_{\max }, t_{\max }$ and AUC) with which to 142 directly compare.

143 Model development and refinement was conducted using the single and multiple doses 144 studies in healthy subjects reported by Guzzo et al. (2002) ${ }^{29}$ (clinical study (i) as detailed 145 above). Model validation was subsequently assessed against clinical studies ii-v (as detailed 146 above). In all cases, model simulations were run to match the reported age range and subject 147 number as reported by each study.

148 Final ivermectin compound parameters that were applied to all subsequent steps are detailed 149 in table 1, with the supplementary materials (Section 1) fully describing the approaches used 150 to determine these parameter values.

\section{$151 \quad 2.2 \quad$ Step 2: Adult escalating dose study}

152 Previous ivermectin clinical studies have used single doses of between $1.4-2 \mathrm{mg} / \mathrm{kg}^{29}{ }^{30}$, and 153 therefore to define a potential upper limit of the therapeutic window, a single oral dose of 2 $154 \mathrm{mg} / \mathrm{kg}$ was administered using a Simcyp predefined healthy volunteer population with 100 155 subjects. The upper therapeutic window band was estimated from the mean maximum 156 concentration within the population group with the lower band set at the LC50 $(16 \mathrm{ng} / \mathrm{mL})^{31}$.

157 Subsequently, simulations were run using the healthy volunteer population aged 18-50 years 158 (100 subjects) with ivermectin dosed orally at $0.15,0.3$ and $0.6 \mathrm{mg} / \mathrm{kg}$ as a single daily dose. 159 Thereafter, the dose resulting in the greatest time above the LC50 (but below the upper limit 160 of the therapeutic window) was selected and assessed under 3-day dosing and 5-day dosing, 161 each with dosing intervals $(\tau)$ of 12- or 24-hours, representing dosing regimens that are 162 widely used for common antimalarials such as artemether, lumefantrine and piperaquine ${ }^{31}$. 163 Finally, the dosing regimen resulting in the greatest time above the LC50 was selected as the 164 optimal dosing regimen in adults.

\section{$165 \quad 2.3 \quad$ Step 3: Paediatric escalating dose study}

166 Simulations were run using the Simcyp paediatric population group and designed to ensure 167 simulations contained at least 100 subjects aged 3-5 years old and covering weight bandings 168 of $15-25 \mathrm{~kg}$. Dose escalation regimens were based on the optimal dose identified in adult 169 population groups (Step 2) with the dosing regimen resulting in the greatest time above the 170 LC50 selected as the optimal dosing regimen in paediatrics (healthy volunteer populations). 
$171 \quad 2.4 \quad$ Step 4-5: Impact of induction-based drug-drug interactions on dosing strategies

172 Many malaria patients are often co-infected with other communicable diseases such as HIV

$173{ }^{41}$. In these cases, the pharmacotherapy requirements are often complex with multiple 174 competing drug-drug interactions (DDIs) possible. Antiretroviral agents such as efavirenz 175 have been demonstrated to induce the expression of CYP3A4 ${ }^{42-44}$ and subsequently increase 176 the metabolic clearance (and hence reduce plasma concentrations) of antimalarial agents ${ }^{45-48}$ 17749 . This may potentially increase the risk of malaria recrudescence and place the patients at 178 risk of developing severe malaria. Therefore the potential risk of CYP3A4 induction on 179 reducing the plasma concentration of ivermectin was assessed in this step.

180 Dosing strategies utilised weight-based dosing for adults (Step 4) and children (Step 5), with 181 simulations run for between 15-21 days ${ }^{50,51}$ with efavirenz dosed throughout the study 182 duration (Adults: $600 \mathrm{mg}$ once daily; Paediatrics: $250 \mathrm{mg}$ once daily for $15 \mathrm{~kg}$ to $<20 \mathrm{~kg}$ and $183300 \mathrm{mg}$ once daily for $20 \mathrm{~kg}$ to $<25 \mathrm{~kg}$ ) and ivermectin dosing initiated at day 13 , to ensure 184 stable induction of CYP3A4 prior to ivermectin dosing. The impact of DDI was assessed 185 through changes in the time above the LC50.

\subsection{Step 6: Ivermectin dosing in a 'malaria-type' population group}

To assess the impact of a potentilal changes in ivermectin pharmacokinetics when dosed in a non-Caucasian/Malaria infected population group, we utilised an Asian (Thailand) population group that was developed in a previous publication by our group to assess antimalarial pharmacokinetics within a malaria-infected population group ${ }^{51}$. This Thai population group was adapted to include appropriate geographical age-weight distributions for male and female adults and paediatrics. These adaptations also included revised blood biochemistry to match patient demographics identified within malaria patients. The development of this Thailand popualtion group is fully described in the Supplementary Materials (Section 2). Simulations were performed based on optimal doses identified in previous sections.

\subsection{Predictive performance}

197 In all of the validation simulations (Step 1), predictions within 2-fold of the observed data 198 were generally considered to represent an 'optimal' predictive performance and confirmed 199 successful model development and validation, despite there being no uniform standard of 200 acceptance to determine this criterion ${ }^{52-54}$. This 2 -fold acceptance criterion was subsequenlty 
201 utilised in comparisons of simulated plasma-concentration profiles with published clinical

202 data, where reported.

203

204

205

206

207

208

209

210

211

212

213

214

215

216

217

218

219

220

221

222

223

224

225

226

227

228

229

\subsection{Data and statistical analysis}

The observed data from clinical studies that were used for visual predictive checks were extracted using WebPlotDigitizer v.3.10 (http://arohatgi.info/WebPlotDigitizer/). Unless otherwise stated, all simulations employing weight-based dosing were run with 100 -subject simulation in a 10x10 trial (10 subjects per trial with 10 trials) to account for reasonable inter/intra individual variability being captured within the model simulations. Where necessary, pooling and post-processing of output Simcyp data were conducted to match individuals to the required age-weight boundary conditions for the study.

Where a DDI was simulated, the model performance was principally dictated by the comparison of the $\mathrm{AUC}$ ratio or $\mathrm{C}_{\max }$ ratio (ratio of the $\mathrm{AUC}$ or $\mathrm{C}_{\max }$ in the absence and presence of the efavirenz). An $\mathrm{AUC}$ ratio or $\mathrm{C}_{\max }$ ratio greater than 1.25 is indicative of an inhibition reaction whereas a ratio of less than 0.8 indicating an induction reaction whilst a ratio of between $0.8-1.25$ indicating no interaction. Where applicable, statistical analysis was conducted using paired t-tests with a $\mathrm{P}<0.05$ indicating statistical significance.

\section{RESULTS}

\subsection{Step 1: Validation}

An ivermectin compound file was developed within Simcyp and validated against a range of published studies using the healthy volunteer population group. Model development considered a range of single ${ }^{29} 35$ and multi-dose studies coupled with more traditional weight based dosing (0.15-0.20 mg/kg) ${ }^{36-39}$, and in all cases simulated ivermectin plasma concentration profiles were within the observed range for each study (Figure 2). Furthermore, the model predicted $t_{\max }, \mathrm{C}_{\max }$ and AUC were predicted to within 2-fold of the reported parameters for each study (Table 2) and confirmed successful model validation.

However, model predicted $\mathrm{AUC}_{0-\mathrm{t}}$ (AUC calculated from the study duration time only) was 3.9-fold underpredicted when compared to the study by Baraka et al (1996) ${ }^{36}$ (Table 2). In contrast, model predicted AUC was within 2-fold when compared to that reported in the 
230 study Okonkwo et al (1993) ${ }^{39}$ for the same dose as that utilised by Baraka et al (1996) ${ }^{36}$ 231 (Table 2).

\section{$232 \quad 3.2 \quad$ Step 2: Adult escalating dose study}

233 Simulations were next performed to assess the impact of dosing-escalation on the time above 234 the suggested LC50 $(16 \mathrm{ng} / \mathrm{ml})$. Single dose studies across a dosing range of $0.15-0.6 \mathrm{mg} / \mathrm{kg}$ 235 (Figure 3A) resulted in a $\mathrm{C}_{\max }$ above the LC50 for all subjects, with higher doses resulting in 236 a longer duration of time above the LC50, 10.4 hours for $0.15 \mathrm{mg} / \mathrm{kg}$ to 23 hours for 0.6 $237 \mathrm{mg} / \mathrm{kg}$ (Table 3). A further dose of $2 \mathrm{mg} / \mathrm{kg}$ resulted in a $\mathrm{C}_{\max }$ of $178.38 \pm 95.98 \mathrm{ng} / \mathrm{mL}$ 238 (Figure 3B) with a duration of time above the LC50 of greater than 24 hours (Table 3). 239 Based upon the $2 \mathrm{mg} / \mathrm{kg}$ dose, the upper 'limit' of the therapeutic window was set at 435.30 $240 \mathrm{ng} / \mathrm{mL}$.

241 Under repeated daily dosing (once daily for 3 days), a similar trend of increasing time above 242 the LC50 with an increasing dose (Table 3) was observed (Figure 3C). The $0.6 \mathrm{mg} / \mathrm{kg}$ dose 243 resulted in time above the LC50 of 152.9 hours (Table 3). Extension of the dosing duration 244 for the $0.6 \mathrm{mg} / \mathrm{kg}$ dose from a single daily dose for 3 days, to a twice daily for 3 days (Figure $2453 \mathrm{D})$ and twice daily dose for 5 days (Figure $3 \mathrm{~F})$ resulted in a significant increase in $\mathrm{C}_{\max }(\mathrm{P}<$ $2460.001)$ and time above LC50 $(151.51 \pm 66.22 \mathrm{ng} / \mathrm{mL}$ and 178.24 hours to $174.41 \pm 73.69$ $247 \mathrm{ng} / \mathrm{mL}$ and 257.19 hours) compared to once daily dosing (Table 3).

\section{$248 \quad 3.3 \quad$ Step 3: Paediatric escalating dose study}

249 Simulations were next performed in healthy paediatric population groups aged 3-5 years to 250 assess the impact of a dosing-escalation on the time above the suggested LC50 (16 ng/ml). 251 As with adult populations, single dose studies across a dosing range of $0.15-0.6 \mathrm{mg} / \mathrm{kg}$ 252 (Figure 4A) resulted in a $\mathrm{C}_{\max }$ above the LC50 which was dose dependant and resulted in a 253 longer duration of time above the LC50, 10.1 hours for $0.15 \mathrm{mg} / \mathrm{kg}$ to 23.9 hours for 0.6 $254 \mathrm{mg} / \mathrm{kg}$ (Table 4). With a higher dose of $2 \mathrm{mg} / \mathrm{kg}$, a $\mathrm{C}_{\max }$ of $348.40 \pm 148.95 \mathrm{ng} / \mathrm{mL}$ was 255 simulated (Figure 4B) which remained above the LC50 for greater than 24 hours (Table 4). 256 Based upon a $2 \mathrm{mg} / \mathrm{kg}$ dose, the upper 'limit' of the therapeutic window was set at 516.91 $257 \mathrm{ng} / \mathrm{mL}$.

258 Repeated daily dosing (once daily for 3 days), resulted in a similar trend of increasing time 259 above the LC50 (Figure 4C) (Table 4) with the largest dose $(0.6 \mathrm{mg} / \mathrm{kg}$ ) resulting in a time 260 above the LC50 of 151.2 hours (Table 4). 
261 Upon extension of the dosing regimen from once daily for 3 days to either twice daily for 3 262 days (Figure 4D), once daily for 5 days (Figure 4E) or twice daily for 5 days (Figure 4F), a 263 significant increase in $\mathrm{C}_{\max }(\mathrm{P}<0.001)$ and time above LC50 compared to once daily dosing 264 (Table 4) was simulated. The longest duration above the LC50 was determined for the twice 265 daily $0.6 \mathrm{mg} / \mathrm{kg}$ dose for 5-days, 290.1 hours (Table 4).

\subsection{Step 4: Impact of induction-based drug-drug interactions on dosing strategies:}

272 To address the potential impact of malaria recrudescence in complex pharmacotherapy, e.g. 273 HIV-coinfection, a DDI was simulated in the presence of the CYP3A4 inducer efavirenz, 274 where the ivermectin dose was escalated. To ensure stable induction of CYP3A4, efavirenz 275 was dosed throughout the simulation period with ivermectin dosing commencing on day 13 276 onwards. Furthermore, dosing was conducted in such a fashion to ensure the ivermectin $\mathrm{C}_{\max }$ 277 did not go beyond the upper therapeutic window identified in step 2.

278 For single daily doses, the impact of efavirenz on ivermectin pharmacokinetics generally 279 resulted in an approximate $50 \%$ decrease in ivermectin $\mathrm{C}_{\max }$ (Figure $\left.5 \mathrm{~A}\right)\left(\mathrm{C}_{\max }\right.$ ratio: 0.48) 280 (Table 5) across all doses $(0.15 \mathrm{mg} / \mathrm{kg}$ to $2 \mathrm{mg} / \mathrm{kg})(\mathrm{P}<0.001)$, with the highest dose 281 resulting in a $\mathrm{C}_{\max }$ of $120.39 \mathrm{ng} / \mathrm{mL} \pm 61.70 \mathrm{ng} / \mathrm{mL}$. Furthermore, the exposure of ivermectin 282 in subjects was also significantly decreased (Figure 5A) with an approximate $75 \%$ decrease 283 in the AUC for across all doses (AUC ratio = 0.28) when compared to the absence of 284 efavirenz $(\mathrm{P}<0.0001)$. The time above the LC50 compared to ivermectin alone (Table 3) 285 was also significantly reduced for all equivalent doses $(\mathrm{P}<0.001)$, for example when 286 comparing the $0.3 \mathrm{mg} / \mathrm{kg}$ dose daily for three days in the absence of efavirenz (time above 287 LC50=86.2 h) (Table 3) to in the presence of efavirenz (time above LC50=19.7 h) (Table 5).

288 When dosing for 3-days (Figure 5B) or 5-days (Figure 5C), $\tau=12$ hours, the $\mathrm{C}_{\max }$ was 289 moderately higher than equivalent single daily doses, however an increase in the AUC was 290 simulated which resulted in a significantly higher time above the LC50 for 3-days ( $1 \mathrm{mg} / \mathrm{kg}$ : 29177.3 hours; $2 \mathrm{mg} / \mathrm{kg}$ : 91.2 hours) or 5-day regimens $(1 \mathrm{mg} / \mathrm{kg}: 138.8$ hours; $2 \mathrm{mg} / \mathrm{kg}: 144.7$ 
292 hours) compared to a single daily dose for three days ( $1 \mathrm{mg} / \mathrm{kg}: 30.8$ hours; $2 \mathrm{mg} / \mathrm{kg}: 47.5$

293 hours) (Table 5) $(\mathrm{P}<0.001)$.

294

295

296

297

298

299

300

301

302

303

304

305

306

307

308

309

310

311

312

313

314

315

316

317

318

319

320

321

322

\subsection{Step 5: Impact of induction-based DDIs on dosing strategies: paediatrics}

The induction effects of efavirenz on CYP3A4 metabolism was further assessed in paediatric subjects, aged 3-5 years and spanning two efavirenz dosing bands $(250 \mathrm{mg}$ for $15 \mathrm{~kg}$ to $<20$ $\mathrm{kg}$ ) and $300 \mathrm{mg}$ for 20 to $<25 \mathrm{~kg}$ ).

For single daily doses, efavirenz exposure resulted in an approximate $57 \%$ decrease in ivermectin $\mathrm{C}_{\max }$ (Figure 6A) $\left(\mathrm{C}_{\max }\right.$ ratio: 0.43) (Table 6) across doses of 0.6, 1 and $2 \mathrm{mg} / \mathrm{kg}$, with the highest dosing regimen ( $2 \mathrm{mg} / \mathrm{kg}$ for three days) resulting in a $\mathrm{C}_{\max }$ of $240.45 \mathrm{ng} / \mathrm{mL}$ $\pm 150.97 \mathrm{ng} / \mathrm{mL}$. This was accompanied by an approximate $79 \%$ decrease in the AUC across all doses $(\mathrm{AUC}$ ratio $=0.21)$ when compared to the absence of efavirenz. (Figure 6A) $(\mathrm{P}<0.001)$. Furthermore, the time above the LC50 compared to ivermectin alone (Table 4) was also significantly reduced $(\mathrm{P}<0.001)$, e.g. comparing the $0.60 \mathrm{mg} / \mathrm{kg}$ dose daily for three days in the absence of efavirenz (time above LC50=151.2 h) (Table 4) to in the presence of efavirenz (time above LC50=27.8 h) (Table 6).

When dosing twice daily for 3-days (Figure 6B) or 5-days (Figure 6C), the simulated $\mathrm{C}_{\max }$ was moderately higher (but not statistically significant) than the equivalent single daily doses (Table 6). This was however accompanied by an increase in the AUC which resulted in a significantly higher time above the LC50 for dosing of twice daily for 3-days ( $1 \mathrm{mg} / \mathrm{kg}: 81.2$ hours; $2 \mathrm{mg} / \mathrm{kg}$ : 104.2 hours) or twice daily for 5-day regimens (1 mg/kg: 141.2 hours; 2 $\mathrm{mg} / \mathrm{kg}$ : 142.2 hours) compared to a single daily dose for three days (1 mg/kg: 30.9 hours; 2 $\mathrm{mg} / \mathrm{kg}: 30.9$ hours) (Table 6).

\subsection{Step 6: Ivermectin dosing in a 'malaria-type' population group}

Although model simulations have been conducted in a healthy volunteer population group, which broadly follows demographic trends in the Caucasian population, the final stage of the modelling process considered the dosing of ivermectin within a non-Caucasian population group, using a custom designed Thailand malarial adult and paediatric population groups which was previously developed and applied to similar malaria modelling approaches by our group ${ }^{51}$, which had appropriate age-weight distributions and associated alterations to blood biochemistry. Ivermectin was dosed at $0.6 \mathrm{mg} / \mathrm{kg}$ once daily for three days to adult (Figure 7A) and paediatrics (Figure 7B). A noticeably lower ivermectin plasma concentrations were 
323 simulated for the Thailand population group compared to the healthy volunteer group (Figure 324 7A) with a similar $\mathrm{C}_{\max }$ for each dose. However, the time above LC50 was significantly 325 reduced in the Thailand population compared to the healthy volunteer population $(\mathrm{P}<0.001)$ 326 (152 hours to 67.3 hours). This was however recoverable when the dosing regimen was 327 increased to $1 \mathrm{mg} / \mathrm{kg}$ and duration extended to once daily for 5 days, resulting in a $\mathrm{C}_{\max }$ of $328176.12 \mathrm{ng} / \mathrm{L} \pm 82.22 \mathrm{ng} / \mathrm{mL}$ and AUC of $4155.15 \mathrm{ng} / \mathrm{mL} . \mathrm{h} \pm 2230.82 \mathrm{ng} / \mathrm{mL} . \mathrm{h}$. Furthermore, 329 the time above LC50 was 171.6 hours.

330 The total oral clearance for ivermectin increased from $39.12 \mathrm{~L} / \mathrm{h} \pm 21.54 \mathrm{~L} / \mathrm{h}$ for the 331 Caucasian healthy adults to $45.2 \mathrm{~L} / \mathrm{h} \pm 27.41 \mathrm{~L} / \mathrm{h}$ for the Thailand subjects.

332 For paediatric subjects, the ivermectin plasma concentration profiles were general similar 333 between Thailand and Caucasian healthy subjects, with a Thailand subjects showing a 334 slightly lower time above LC50, 137.2 hours compared to Caucasian healthy subjects, 154.8 335 hours (Figure 7B).

\section{$336 \quad 4 . \quad$ DISCUSSION}

337 The eradication of malaria has been successful in many countries through the use of 338 artemisinin-based combination therapy (ACT) ${ }^{1}$. However, this optimism has recently been 339 tempered by the appearance of artemisinin-resistance Plasmodium falciparum strains in the $340 \mathrm{GMS}^{7-10}$. Despite the urgent need for new antimalarial agents to tackle this increasing risk of 341 resistance, the time-lag associated with the discovery/development and clinical assessment of 342 new drugs precludes the imminent regulatory approval of pipeline candidates ${ }^{55}$. However, 343 drug repurposing provides an approach whereby existing licenced drugs can be 'transferred' 344 to an alternative (proven) indication, thereby bypassing the need for traditional 345 discovery/development pipelines. Such approaches have indeed been useful in repurposing 346 thalidomide to treat multiple myeloma ${ }^{56}$ and crizotinib ${ }^{57}$ for anaplastic lymphoma kinase 347 gene-rearranged non-small cell lung cancer.

348 Recent reports have highlighted ivermectin as a potential candidate for repurposing towards 349 malaria ${ }^{22-24}$. Ivermectin is a dihydro derivate of avermectin and was initially licenced for use 350 in veterinary medicines, but has demonstrated immense success in the treatment of 351 Onchocerciasis in addition to a range of other nematode infections including Ascariasis, 352 filariases, Gnathostomiasis and Trichuriasis ${ }^{58}$. Further, reports have also highlighted how 353 ivermectin can remain in the blood stream for a sufficiently long time-frame to kill the 354 Anopheline vector ${ }^{15-19}$ and malaria parasite ${ }^{20}$. A key advantage of ivermectin therapy is that, 
355 given its wide scale global use with many decades of monotherapy, there is yet to be 356 confirmed scenarios of ivermectin resistance, leading to calls for ivermectin to be given 357 consideration for other potential communicable diseases ${ }^{22-24,59}$.

358 The primary aim of this study was to explore the possible use of ivermectin dosing in adult 359 and paediatric subjects using PBPK modelling through virtual clinical trials analysis. Such 360 approaches have been previously employed by our group to explore the role of anti-malarial 361 agents in special population groups such as paediatrics ${ }^{50}$ and pregnant women ${ }^{51}$.

362 The primary objectives of this study were to: (i) assess the impact of dose escalation of 363 ivermectin on adult (20-50 years old) and paediatric (3-5 years old) populations; (ii) assess 364 the impact of inducted based drug-drug interactions on reducing ivermectin plasma 365 concentrations in adults and children and (iii) to assess the impact of optimal dose of 366 ivermectin on a representative malaria population group (Thailand).

367 The development of ivermectin as a compound file within Simcyp was focussed around 368 utilising existing clinical studies reporting either full plasma concentration-time profiles or 369 sparse sampling time-points with which to develop and drive appropriate predictions of 370 ivermectin concentrations. The studies chosen represented a broad range of single ${ }^{29,35}$ and 371 multiple dose studies ${ }^{29}$ coupled with standard ${ }^{36-39}$ and higher dose studies ${ }^{29,35}$.

372 In the validation of the ivermectin compound file, it was necessary to address the role of 373 active efflux on the intestinal drug absorption, particularly as ivermectin is known to be 374 subjected to active efflux through P-glycoprotein ${ }^{60}$. However, in light of the lack of any in375 vitro reported kinetic parameters describing active efflux, namely the apparent Vmax 376 (maximum velocity) estimated for the carrier system (Jmax) and the Michaelis constant (km), 377 we incorporated an active efflux component for ivermectin through assuming the active 378 efflux of ivermectin was initially similar to that of digoxin. The impact of this assumption 379 was first confirmed through a sensitivity analysis (Supplementary materials: Section 1), 380 which demonstrated that the choice of digoxin in vitro transporter-mediated intrinsic 381 clearance (CLint P-glycoprotein $_{\text {) }}$ of $2.5 \mu \mathrm{L} / \mathrm{min}$, and associated relative activity factor (0.1) was 382 sufficient to capture an appropriate $\mathrm{t}_{\max }$ and $\mathrm{C}_{\max }$ for a $60 \mathrm{mg}$ single dose of ivermectin ${ }^{61}$.

383 This approach was further extended to all model simulations in Step 1, and demonstrated 384 successful validation for clinical studies ii-v (see section 2.1) (Figure 2), with all predicted 385 pharmacokinetic parameters residing within the range of literature reported values for all 
386 dosing regimens simulated, and in particular the $\mathrm{C}_{\max }, \mathrm{t}_{\max }$ and AUC predictions all within 2387 fold of those reported by each clinical study (Table 2).

388 However, model simulations were unable to capture the $\mathrm{AUC}_{0-\mathrm{t}}$ reported by Baraka et al 389 (1996) ${ }^{36}$. It is possible that the mismatch may have been attributed to the population group 390 utilised for the Baraka study, namely Sudanese, where age-weight relationships have 391 highlighted an overall lower adult weight compared to healthy volunteers (Caucasian) 392 populations ${ }^{62}$. It is also unclear from the Baraka study whether $\mathrm{AUC}_{0-\mathrm{t}}$ or $\mathrm{AUC}_{\text {inf }}(\mathrm{AUC}$ 393 extrapolated to infinity) was reported. Furthermore, despite this underprediction, our model 394 predicted $\mathrm{AUC}_{0-\mathrm{t}}$ was within 2-fold of that reported by Okonkwo et al (1993) ${ }^{39}$, which 395 utilised an identical dose and dosing regimen as Baraka et al (1996) ${ }^{36}$. Having successfully demonstrated validation of the ivermectin compound file, we next assessed the impact of dose-escalation on the both the $\mathrm{C}_{\max }$, exposure (AUC) and time above 398 the LC50 $(16 \mathrm{ng} / \mathrm{mL})^{31}$. Although a key metric for success with antimalarial agents is the day-7 concentration, this information is lacking with ivermectin. The LC50 provides a suitable metric with which to develop an 'exposure-time' relationship. Whilst this has not been fully described within malaria subjects, recent reports have identified LC50 for Anopheles minimus $(\mathrm{LC50}=16.3 \mathrm{ng} / \mathrm{ml})$, Anopheles campestris $(\mathrm{LC} 50=26.4 \mathrm{ng} / \mathrm{ml})$, Anopheles sawadwongporni $(\mathrm{LC} 50=26.9 \mathrm{ng} / \mathrm{ml})$ and Anopheles. dirus $(\mathrm{LC} 50=55.6 \mathrm{ng} / \mathrm{ml})$ 404 31. Given that Anopheles minimus is the primary malaria vector within the GMS ${ }^{63}$, it was assumed that an LC50 of $16 \mathrm{ng} / \mathrm{mL}$ would form the lower spectrum of a potential therapeutic window. Weight-based dose-escalation over $0.15 \mathrm{mg} / \mathrm{kg}$ (standard dose) to $0.60 \mathrm{mg} / \mathrm{kg}$ for 407 single doses (Figure 3A) resulted in a clear increase in $\mathrm{C}_{\max }$ and time above the LC50 (Table 4083 ), with a higher dose of $2 \mathrm{mg} / \mathrm{kg}$ (Figure 3B) resulting in a time above the LC50 $>24$ hours 409 (Table 3).

410 A $2 \mathrm{mg} / \mathrm{kg}$ dose have been previously clinically administered ${ }^{29}$, with the Centre for Disease 411 Control and Prevention recommending doses of up to $1.4 \mathrm{mg} / \mathrm{kg}$ for severe crusted scabies ${ }^{30}$. 412 Here, we assumed that a dose of $2 \mathrm{mg} / \mathrm{kg}$ would be a realistic 'safe' maximum upper daily 413 dose, given that it was clinically used with no serious adverse reactions in subjects ${ }^{29}$. It was 414 decided to set the upper limit of a possible therapeutic window at the population simulated 415 mean $\mathrm{C}_{\max }, 435.20 \mathrm{ng} / \mathrm{mL}$ for adults and $516.91 \mathrm{ng} / \mathrm{mL}$ for children.

416 Therefore, assuming the therapeutic window ranged from $16 \mathrm{ng} / \mathrm{mL}$ to $435.20 \mathrm{ng} / \mathrm{mL}$ (or $417516.91 \mathrm{ng} / \mathrm{mL}$ for paediatrics), we assessed the impact of multiple dosing regimens on time 
418 above the LC50 (Figure 3C-F). As expected, a decrease in dosing interval ( $\tau=24$ hours to 12 419 hours) and increase in dosing regimen duration (3-days or 5 days) resulted in a proportional 420 increase in $\mathrm{C}_{\max }$ and time above LC50 (Table 3). However, the overall increase in the $\mathrm{C}_{\max }$ 421 was minimal when comparing single doses with equivalent doses over 3 days (e.g. $0.6 \mathrm{mg} / \mathrm{kg}$ 422 single dose: $95.86 \mathrm{ng} / \mathrm{mL} \pm 31.72 \mathrm{ng} / \mathrm{mL}$ and daily for 3 days $113.11 \mathrm{ng} / \mathrm{mL} \pm 39.54 \mathrm{ng} / \mathrm{mL}$ 423 (Table 3). This was accompanied by an increase in the overall exposure (e.g. $0.6 \mathrm{mg} / \mathrm{kg}$ 424 single dose: $960.29 \mathrm{ng} / \mathrm{mL} . \mathrm{h} \pm 335.66 \mathrm{ng} / \mathrm{mL} . \mathrm{h}$ and daily for 3 days $3581.99 \mathrm{ng} / \mathrm{mL} . \mathrm{h} \pm$ $4251777.58 \mathrm{ng} / \mathrm{mL} . \mathrm{h}$ ) and associated with an increase in the LC50 from 23.2 hours to 152.9 426 hours. Thus, the extension of a treatment duration from a single dose to a three-day or five427 day treatment regimen would significantly enhance overall ivermectin exposure within the 428 therapeutic window and enhance exposure for approximately 7-11 days. Multiple dosing 429 regimens have previously been used on Onchocerca volvulus ${ }^{64,65}$ and Wuchereria bancrofti $430 \quad 66$ and which has been well tolerated.

431

432 A key benefit of PBPK modelling is the ability to pragmatically assess the pharmacokinetics 433 of a drug in different population groups, and we next predicted the potential 434 pharmacokinetics in children aged 3-5 years, primarily based upon the recommended weight 435 minimum weight of $15 \mathrm{~kg}$. We attempted to develop both an appropriate therapeutic range in 436 paediatrics and identify the optimal treatment regimens to prolong the time above the LC50. 437 We utilised the same dosing approaches as adults and identified $516.91 \mathrm{ng} / \mathrm{mL}$, as being the 438 potential upper limit for a proposed therapeutic window, based upon doing at $2 \mathrm{mg} / \mathrm{kg}$. 439 Although this is dosing regimen used in adults, it is below the dose of approximately 7-8 $440 \mathrm{mg} / \mathrm{kg}$ used in reports of a child who demonstrated ivermectin toxicity ${ }^{67}$.

442 As with adults, increasing single doses (Figure 4A) resulted in increases in $\mathrm{C}_{\max }$ and AUC 443 with a longer time above the LC50 (Table 4). Furthermore, a similar increase in dosing 444 interval and duration (Figure 4C-E) resulting in a proportional increase in time above the 445 LC50 (Table 4), with the $0.6 \mathrm{mg} / \mathrm{kg}$ twice daily for 5 days resulting in the longest time above 446 the LC50 (290.1 ng/mL or 41.4 days), similar to that obtained in adults, 257.19 hours (Table $4473)$.

448

449 Thus, for both adults and children, a higher dose of $0.6 \mathrm{mg} / \mathrm{kg}$ administered twice daily for 3 450 or 5 days, leads to significantly higher $C_{\max }$ values compared to their corresponding single 
451 daily doses whilst also providing a longer duration above the LC50. When considering the 452 potential problem of the lack of medication compliance with extended dosing of medicines, a 453 3-day regimen may be an appropriate dosing regimen administered twice daily, to ensure 454 prolonged duration above the LC50 of 9-11 days.

455 Under standard dosing conditions, a 3-day regimen may be an appropriate way to ensuring 456 prolonged effects. However, many malaria patients are often co-infected with other 457 communicable diseases such as Tuberculosis ${ }^{41,68-70}$ or HIV ${ }^{41}$. In these cases, the 458 pharmacotherapy requirements are often complex with multiple competing drug-drug 459 interactions (DDIs) possible. Previously we have illustrated the impact of induction-based 460 DDIs on the reducing the plasma concentration of lumefantrine under dosing with rifampicin 461 (a CYP3A4 inducer) ${ }^{50}$, and this step next considered a similar DDI with the use of the 462 antiretroviral efavirenz to simulate HIV-coinfected malaria subjects to ultimately assess the 463 impact of the DDI on reducing ivermectin plasma concentrations.

464 In all simulations with adults (Figure 5) or paediatrics (Figure 6), the exposure to efavirenz 465 (250 mg once daily for $15 \mathrm{~kg}$ to $<20 \mathrm{~kg}$ and $300 \mathrm{mg}$ once daily for $20 \mathrm{~kg}$ to $<25 \mathrm{~kg}$ ) 466 significantly reduced ivermectin $C_{\max }$, exposure (AUC) and time above the LC50 for all 467 dosing regimens (Table 5 and 6). The impact of this DDI can be assessed through the AUC 468 ratio or $\mathrm{C}_{\max }$ ratio, which indicate significant decreases in both AUC ratio (0.21-0.28) and $469 \mathrm{C}_{\max }$ ratio (0.39-0.48) for adult studies (Table 5) and a greatest decrease in paediatrics (AUC: $470 \quad 0.19-0.21 ; \mathrm{C}_{\max }: 0.36-0.43$ ) (Table 6) across all dosing regimens.

471 In trying to overcome the reduced exposure of ivermectin in the presence of a CYP3A4 472 inducer, the use of $1 \mathrm{mg} / \mathrm{kg}$ or $2 \mathrm{mg} / \mathrm{kg}$ twice daily for five days in adults and children would 473 achieve the greatest time above the LC50 (adults: 138.8 hours and 144.7 hours respectively; 474 paediatrics: 141.2 hours and 142.1 hours respectively).

475 The focus of this study has generally been towards establishing appropriate dosing regimens 476 for ivermectin for use in malaria infected subjects. However, the marked differences in 477 global age-body weight relationships ${ }^{62}$ would clearly alter the establishment of dosing 478 regimens and would, in theory, render a 'one-dose-fits-all' approach inappropriate. Our 479 group has recently utilised a geographic-region specific malaria population group for virtual 480 clinical trials simulation ${ }^{51}$. We adapted this population group for use in the present study 481 and developed a simplistic representative Thailand population group with appropriate body 482 weight distribution for adults and paediatric subjects, whilst also incorporating appropriate 
483 changes in blood biochemistry often observed in malaria-infected patients ${ }^{51}$. Using this 484 approach, we demonstrated a significant difference in the simulated ivermectin plasma 485 concentration from a $0.60 \mathrm{mg} / \mathrm{kg}$ daily dose for 3 days regimen (Figure 7A), with a 486 statistically significant 84.7 hours decrease in the time above LC50 in the Thailand 487 population compared to the heathy volunteer population. As dosing was focused on weight488 based approaches, the differences in the median body weight for the simulated Thailand 489 population group, $49.86 \mathrm{~kg} \pm 10.25 \mathrm{~kg}$, compared to the healthy volunteer group, $69.41 \mathrm{~kg} \pm$ $49014.29 \mathrm{~kg}$, would therefore alter resultant ivermectin plasma concentration and exemplified the 491 needs to consider population-based age-weight distribution data, as exemplified by the study 492 by Hayes et al (2015) ${ }^{62}$, to develop more appropriate weight-based dosing regimen for 493 malaria endemic regions. By addressing this potential disparity between body weights, the 494 dosing regimen was adapted to $1 \mathrm{mg} / \mathrm{kg}$, and this could recapture the time above LC50 to a 495 similar extent as that observed in the healthy volunteer population group (Figure 7A). It 496 should be noted that the neutral charge of ivermectin would likely result in preferential 497 binding to human serum albumin (HSA). However, HSA is known to decrease in malaria 498 subjects along with changes in both the haematocrit and alpha-one acidic glycoprotein ${ }^{51}$. 499 This decrease in HSA would be expected to increase both the volume of distribution of 500 ivermectin and more importantly, alter its hepatic extraction, particularly given that 501 ivermectin is highly protein bound ${ }^{71}$. An analysis of the oral clearance demonstrated a 502 significant $(\mathrm{P}<0.01)$ increase in Thailand subjects compared to healthy volunteers, and this 503 also accounts for the lower overall plasma concentrations. Interesting, a similar trend was not 504 observed in the paediatric population, with simulated ivermectin concentration broadly 505 similar in both population group (Figure 7B)

507 It should, however, be noted that currently marketed ivermectin contains a mixture termed 508 ivermectin B1a, consisting of an ethyl group at the C-26 position, and ivermectin B1b 509 containing a methyl group ${ }^{72}$, in an at least $80 \% \mathrm{~B} 1 \mathrm{a}$ and no more than $20 \% \mathrm{~B} 1 \mathrm{~b}$ mixture ${ }^{73}$. 510 Thus, the possibility of wide variability in ivermectin form within each dosing unit may 511 introduce a wide variation of clinical dose response. Given the possibility of a relatively 512 wide therapeutic window, the impact of such variability may be contained. However further 513 work is required to define the exact duration above the LC50 required to sustain an effect. 
515 The work presented in this study demonstrates the application of PBPK modelling to the 516 successful development and validation of a PBPK model for ivermectin. This has allowed 517 the pragmatic assessment of different dosing regimen designs on ivermectin plasma 518 concentrations in liue of clinical trials. Whilst the work presented in this study is not 519 intended to replace future clinical trials assessment of ivermectin in the context of malaria 520 treatment, it can be used to guide and assess other novel dosing regimens or in complex 521 special population groups. However, despite the large number of clinical studies in adults, 522 there is a distinct sparsity in the availability of clinical studies examining ivermectin 523 pharmacokinetics in children, and to fully exploit ivermectin in the context of malaria, urgent 524 clinical trials are required to assess the safety and efficacy of ivermectin in children at doses 525 identified within this study for use in malaria, particularly in the event of an CYP3A4526 mediated induction DDI.

527 Further, the lack of kinetic parameters for P-glycoprotein efflux (Jmax and km) would 528 warrant attention placed on elucidating appropriate in-vitro Caco-2 P-glycoprotein kinetic 529 efflux parameters to improve future model predictions. However, using the kinetic 530 parameters associated with digoxin efflux, the model was able appropriately capture this 531 efflux $a b$ orally and yield estimates suitable estimates of $t_{\max }$ during the model development 532 and for all clinical studies used during the validation stage (Step 1). The model provided will 533 therefore allow for future refinement when this information becomes available.

534 Given that ivermectin is a highly lipophilic compound ${ }^{74}$, it is likely that its oral absorption 535 and oral bioavailability will be enhanced with fat-rich meals, in a similar fashion to other 536 antimalarial agents, e.g. artemether ${ }^{75,76}$ and lumefantrine ${ }^{76}$. This would also require 537 consideration of the impact of biorelevant 'fed' dissolution media on the in-vitro dissolution 538 rate of ivermectin from a solid dosage formulation. Such data is lacking for the majority of 539 currently used antimalarial agents, and if determined for ivermectin, the proposed model can 540 be adapted to include cumulative percentage release information for fasted and fed states 541 which will allow exploration of the impact of fat-rich meals on ivermectin solubility and 542 dissolution.

\section{CONCLUSION}

544 Although malaria eradication has had wide ranging global successes, the appearance of 545 artemisinin-based combination therapy resistance in the GMS requires urgent attention to the 546 development of new anti-malarial drugs. Traditional discovery/development pipelines may 
547 not accommodate the swift reaction that is required, and repurposing of alternative drug 548 therapies may provide a novel approach to discover new therapies for malaria. Ivermectin is 549 one such drug which has gained attention as a potential candidate. This study has further 550 added to the understanding of the possibility of using ivermectin in a clinical setting within 551 diverse population groups. The dosing regimens simulated are similar to existing therapeutic 552 regimens, and given the wide therapeutic dosing range, provides further support for the 553 repurposing of ivermectin to malaria.

554

555 ACKNOWLEDGEMENTS

556 This research did not receive any specific grant from funding agencies in the public, 557 commercial, or not-for-profit sectors.

558

\section{REFERENCES}

560 1. Organization WH 2016. Global Technical Strategy for Malaria 2016-2030. 2015. 561 Geneva 35pp.

562 2. White NJ 2004. Antimalarial drug resistance. Journal of Clinical Investigation 563 113(8):1084-1092.

$5643 . \quad$ Payne D 1987. Spread of chloroquine resistance in Plasmodium falciparum. 565 Parasitology today (Personal ed) 3(8):241-246.

566 4. Roper C, Pearce R, Bredenkamp B, Gumede J, Drakeley C, Mosha F, Chandramohan 567 D, Sharp B 2003. Antifolate antimalarial resistance in southeast Africa: a population-based 568 analysis. Lancet (London, England) 361(9364):1174-1181.

5695 5. Nair S, Williams JT, Brockman A, Paiphun L, Mayxay M, Newton PN, Guthmann JP, 570 Smithuis FM, Hien TT, White NJ, Nosten F, Anderson TJ 2003. A selective sweep driven by 571 pyrimethamine treatment in southeast asian malaria parasites. Molecular biology and 572 evolution 20(9):1526-1536.

573 6. Dondorp AM, Nosten F, Yi P, Das D, Phyo AP, Tarning J, Lwin KM, Ariey F, 574 Hanpithakpong W, Lee SJ, Ringwald P, Silamut K, Imwong M, Chotivanich K, Lim P, 575 Herdman T, An SS, Yeung S, Singhasivanon P, Day NPJ, Lindegardh N, Socheat D, 576 White NJ 2009. Artemisinin Resistance in Plasmodium falciparum Malaria. New England 577 Journal of Medicine 361(5):455-467.

578 7. Spring MD, Lin JT, Manning JE, Vanachayangkul P, Somethy S, Bun R, Se Y, Chann 579 S, Ittiverakul M, Sia-ngam P, Kuntawunginn W, Arsanok M, Buathong N, Chaorattanakawee 580 S, Gosi P, Ta-aksorn W, Chanarat N, Sundrakes S, Kong N, Heng TK, Nou S, Teja581 isavadharm P, Pichyangkul S, Phann ST, Balasubramanian S, Juliano JJ, Meshnick SR, 582 Chour CM, Prom S, Lanteri CA, Lon C, Saunders DL 2015. Dihydroartemisinin-piperaquine 583 failure associated with a triple mutant including kelch13 C580Y in Cambodia: an 584 observational cohort study. The Lancet Infectious Diseases 15(6):683-691.

585 8. Leang R, Taylor WR, Bouth DM, Song L, Tarning J 2015. Evidence of Plasmodium 586 falciparum Malaria Multidrug Resistance to Artemisinin and Piperaquine in Western 
587 Cambodia: Dihydroartemisinin-Piperaquine Open-Label Multicenter Clinical Assessment. 588 59(8):4719-4726.

589 9. Phyo AP, Ashley EA, Anderson TJC, Bozdech Z, Carrara VI, Sriprawat K, Nair S, 590 White MM, Dziekan J, Ling C, Proux S, Konghahong K, Jeeyapant A, Woodrow CJ, W. Mready R, Lwin KM, Day NPJ, White NJ, Nosten F 2016. Declining Efficacy of Artemisinin Combination Therapy Against P. Falciparum Malaria on the Thai-Myanmar Border (2003-2013): The Role of Parasite Genetic Factors. Clinical Infectious Diseases 63(6):784-791.

10. Amaratunga C, Lim P, Suon S, Sreng S, Mao S, Sopha C, Sam B, Dek D, Try V, Amato R, Blessborn D, Song L, Tullo GS, Fay MP, Anderson JM, Tarning J, Fairhurst RM 2016. Dihydroartemisinin-piperaquine resistance in Plasmodium falciparum malaria in Cambodia: a multisite prospective cohort study. The Lancet Infectious Diseases 16(3):357365 .

11. Lotharius J, Gamo-Benito FJ, Angulo-Barturen I, Clark J, Connelly M, Ferrer-Bazaga S, Parkinson T, Viswanath P, Bandodkar B, Rautela N, Bharath S, Duffy S, Avery VM, Möhrle JJ, Guy RK, Wells T 2014. Repositioning: the fast track to new anti-malarial medicines? Malaria journal 13(1):143.

12. Sardana D, Zhu C, Zhang M, Gudivada RC, Yang L, Jegga AG 2011. Drug repositioning for orphan diseases. Briefings in Bioinformatics 12(4):346-356.

13. Ōmura S, Crump A 2017. Ivermectin and malaria control. Malaria journal 16(1):172.

14. Richards FO 2017. Upon entering an age of global ivermectin-based integrated mass drug administration for neglected tropical diseases and malaria. Malaria journal 16(1):168. 15. Tesh RB, Guzman H 1990. Mortality and infertility in adult mosquitoes after the ingestion of blood containing ivermectin. The American journal of tropical medicine and hygiene 43(3):229-233.

16. Chaccour C, Lines J, Whitty CJ 2010. Effect of ivermectin on Anopheles gambiae mosquitoes fed on humans: the potential of oral insecticides in malaria control. The Journal of infectious diseases 202(1):113-116.

17. Kobylinski KC, Deus KM, Butters MP, Hongyu T, Gray M, da Silva IM, Sylla M, Foy BD 2010. The effect of oral anthelmintics on the survivorship and re-feeding frequency of anthropophilic mosquito disease vectors. Acta tropica 116(2):119-126.

18. Kobylinski KC, Sylla M, Chapman PL, Sarr MD, Foy BD 2011. Ivermectin mass drug administration to humans disrupts malaria parasite transmission in Senegalese villages. The American journal of tropical medicine and hygiene 85(1):3-5.

19. Foy BD, Kobylinski KC, da Silva IM, Rasgon JL, Sylla M 2011. Endectocides for malaria control. Trends in parasitology 27(10):423-428.

20. Panchal M, Rawat K, Kumar G, Kibria K, Singh S, Kalamuddin M, Mohmmed A, Malhotra P, Tuteja R 2014. Plasmodium falciparum signal recognition particle components and anti-parasitic effect of ivermectin in blocking nucleo-cytoplasmic shuttling of SRP. Cell death \& disease 5(1):e994.

21. Chaccour CJ, Rabinovich NR, Slater H, Canavati SE, Bousema T, Lacerda M, ter Kuile F, Drakeley C, Bassat Q, Foy BD, Kobylinski K 2015. Establishment of the Ivermectin Research for Malaria Elimination Network: updating the research agenda. Malaria journal 14(1):243.

22. Chaccour C, Hammann F, Rabinovich NR 2017. Ivermectin to reduce malaria transmission I. Pharmacokinetic and pharmacodynamic considerations regarding efficacy and safety. Malaria journal 16(1):161.

23. Chaccour C, Rabinovich NR 2017. Ivermectin to reduce malaria transmission II. Considerations regarding clinical development pathway. Malaria journal 16(1):166. 
636 24. Chaccour C, Rabinovich NR 2017. Ivermectin to reduce malaria transmission III.

637 Considerations regarding regulatory and policy pathways. Malaria journal 16(1):162.

638 25. Canga AG, Prieto AMS, Liébana MJD, Martínez NF, Vega MS, Vieitez JJG 2008.

639 The pharmacokinetics and interactions of ivermectin in humans - a mini-review. The AAPS 640 journal 10(1):42-46.

641 26. Edwards G, Dingsdale A, Helsby N, Orme ME, Breckenridge A 1988. The relative 642 systemic availability of ivermectin after administration as capsule, tablet, and oral solution. 643 European journal of clinical pharmacology 35(6):681-684.

644 27. Zeng Z, Andrew N, Arison B, Luffer-Atlas D, Wang R 1998. Identification of 645 cytochrome P4503A4 as the major enzyme responsible for the metabolism of ivermectin by 646 human liver microsomes. Xenobiotica; the fate of foreign compounds in biological systems 647 28(3):313-321.

648 28. Lawrence J, Sodahlon YK, Ogoussan KT, Hopkins AD 2015. Growth, Challenges, 649 and Solutions over 25 Years of Mectizan and the Impact on Onchocerciasis Control. PLOS 650 Neglected Tropical Diseases 9(5):e0003507.

651 29. Guzzo CA, Furtek CI, Porras AG, Chen C, Tipping R, Clineschmidt CM, Sciberras

652 DG, Hsieh JYK, Lasseter KC 2002. Safety, tolerability, and pharmacokinetics of escalating 653 high doses of ivermectin in healthy adult subjects. The Journal of Clinical Pharmacology 654 42(10):1122-1133.

655 30. CDC. 2016. Prescription medication for the treatment of scabies. . ed., USA.

656 31. Kobylinski KC, Ubalee R, Ponlawat A, Nitatsukprasert C, Phasomkulsolsil S,

657 Wattanakul T, Tarning J, Na-Bangchang K, McCardle PW, Davidson SA, Richardson JH

658 2017. Ivermectin susceptibility and sporontocidal effect in Greater Mekong Subregion

659 Anopheles. Malaria journal 16(1):280.

660 32. Johnson TN 2005. Modelling approaches to dose estimation in children. Brit J Clin 661 Pharmaco 59(6):663-669.

662 33. Johnson TN 2008. The problems in scaling adult drug doses to children. Archives of 663 disease in childhood 93(3):207-211.

664 34. Small BG, Wendt B, Jamei M, Johnson TN 2017. Prediction of liver volume - a

665 population-based approach to meta-analysis of paediatric, adult and geriatric populations - an 666 update. Biopharmaceutics \& drug disposition.

667 35. Edwards G, Dingsdale A, Helsby N, Orme ML, Breckenridge AM 1988. The relative 668 systemic availability of ivermectin after administration as capsule, tablet, and oral solution.

669 European journal of clinical pharmacology 35(6):681-684.

670 36. Baraka OZ, Mahmoud BM, Marschke CK, Geary TG, Homeida MMA, Williams JF

671 1996. Ivermectin distribution in the plasma and tissues of patients infected with Onchocerca

672 volvulus. European journal of clinical pharmacology 50(5):407-410.

673 37. Na-Bangchang K, Banmairuroi V, Choemung A 2006. High-performance liquid 674 chromatographic method for the determination of ivermectin in plasma. Southeast Asian J 675 Trop Med Public Health 37(5):848-858.

676 38. Njoo FL, Beek WMJ, Keukens HJ, Van Wilgenburg H, Oosting J, Stilma JS, Kijlstra 677 A 1995. Ivermectin Detection in Serum of Onchocerciasis Patients: Relationship to Adverse 678 Reactions. The American Journal of Tropical Medicine and Hygiene 52(1):94-97.

679 39. Okonkwo PO, Ogbuokiri JE, Ofoegbu E, Klotz U 1993. Protein binding and 680 ivermectin estimations in patients with onchocerciasis. Clinical Pharmacology \& 681 Therapeutics 53(4):426-430.

682 40. Ouédraogo AL, Bastiaens GJH, Tiono AB, Guelbéogo WM, Kobylinski KC, 683 Ouédraogo A, Barry A, Bougouma EC, Nebie I, Ouattara MS, Lanke KHW, Fleckenstein L, 684 Sauerwein RW, Slater HC, Churcher TS, Sirima SB, Drakeley C, Bousema T 2015. Efficacy 685 and Safety of the Mosquitocidal Drug Ivermectin to Prevent Malaria Transmission After 
686 Treatment: A Double-Blind, Randomized, Clinical Trial. Clinical Infectious Diseases 687 60(3):357-365.

688 41. Jegede FE, Oyeyi TI, Abdulrahman SA, Mbah HA, Badru T, Agbakwuru C, 689 Adedokun O 2017. Effect of HIV and malaria parasites co-infection on immune-

690 hematological profiles among patients attending anti-retroviral treatment (ART) clinic in 691 Infectious Disease Hospital Kano, Nigeria. PLoS One 12(3):e0174233.

692 42. Habtewold A, Amogne W, Makonnen E, Yimer G, Nylén H, Riedel KD 2013.

693 Pharmacogenetic and pharmacokinetic aspects of CYP3A induction by efavirenz in HIV

694 patients. Pharmacogenomics J 13.

695 43. Hariparsad N, Nallani SC, Sane RS, Buckley DJ, Buckley AR, Desai PB 2004.

696 Induction of CYP3A4 by efavirenz in primary human hepatocytes: comparison with rifampin

697 and phenobarbital. Journal of clinical pharmacology 44(11):1273-1281.

698 44. Mouly S, Lown KS, Kornhauser D, Joseph JL, Fiske WD, Benedek IH, Watkins PB

699 2002. Hepatic but not intestinal CYP3A4 displays dose-dependent induction by efavirenz in

700 humans. Clinical Pharmacology \& Therapeutics 72(1):1-9.

701 45. Byakika-Kibwika P, Lamorde M, Mayito J, Nabukeera L, Namakula R, Mayanja-

702 Kizza H 2012. Significant pharmacokinetics interactions between artemether/lumefantrine

703 and efavirenz or in HIV-infected Ugandan adults. J Antimicrob Chemother 67.

704 46. Fillekes Q, Natukunda E, Balungi J, Kendall L, Bwakura-Dangarembizi M,

705 Keishanyu R, Ferrier A, Lutakome J, Gibb DM, Burger DM, Walker AS 2011. Pediatric

706 underdosing of efavirenz: a pharmacokinetic study in Uganda. J Acquir Immune Defic Syndr

707 58(4):392-398.

708 47. Huang L, Parikh S, Rosenthal PJ, Lizak P, Marzan F, Dorsey G 2012. Concomitant

709 efavirenz reduces pharmacokinetic exposure to the antimalarial drug artemether-lumefantrine 710 in healthy volunteers. J Acquir Immune Defic Syndr 61.

711 48. Maganda BA, Minzi OM, Ngaimisi E, Kamuhabwa AA, Aklillu E 2016. CYP2B6*6

712 genotype and high efavirenz plasma concentration but not nevirapine are associated with low

713 lumefantrine plasma exposure and poor treatment response in HIV-malaria-coinfected

714 patients. Pharmacogenomics J 16(1):88-95.

715 49. Maganda BA, Ngaimisi E, Kamuhabwa AA, Aklillu E, Minzi OM 2015. The

716 influence of nevirapine and efavirenz-based anti-retroviral therapy on the pharmacokinetics

717 of lumefantrine and anti-malarial dose recommendation in HIV-malaria co-treatment. Malaria

718 journal 14(1):179.

719 50. Olafuyi O, Coleman M, Badhan RKS 2017. Development of a paediatric

720 physiologically based pharmacokinetic model to assess the impact of drug-drug interactions

721 in tuberculosis co-infected malaria subjects: A case study with artemether-lumefantrine and

722 the CYP3A4-inducer rifampicin. Eur J Pharm Sci 106:20-33.

723 51. Olafuyi O, Coleman M, Badhan RKS 2017. The application of physiologically based

724 pharmacokinetic modelling to assess the impact of antiretroviral-mediated drug-drug

725 interactions on piperaquine antimalarial therapy during pregnancy.

726 52. Ginsberg G, Hattis D, Russ A, Sonawane B 2004. Physiologically based

727 pharmacokinetic (PBPK) modeling of caffeine and theophylline in neonates and adults:

728 Implications for assessing children's risks from environmental agents. Journal of Toxicology

729 and Environmental Health-Part a-Current Issues 67(4):297-329.

730 53. Edginton AN, Schmitt W, Willmann S 2006. Development and evaluation of a

731 generic physiologically based pharmacokinetic model for children. Clinical Pharmacokinetics

732 45(10):1013-1034.

733 54. Parrott N, Davies B, Hoffmann G, Koerner A, Lave T, Prinssen E, Theogaraj E,

734 Singer T 2011. Development of a Physiologically Based Model for Oseltamivir and 
Simulation of Pharmacokinetics in Neonates and Infants. Clinical Pharmacokinetics 50(9):613-623.

737 55. White NJ 2010. Artemisinin resistance - the clock is ticking. The Lancet

738 376(9758):2051-2052.

739 56. Breitkreutz I, Anderson KC 2008. Thalidomide in multiple myeloma--clinical trials

740 and aspects of drug metabolism and toxicity. Expert opinion on drug metabolism \&

741 toxicology 4(7):973-985.

742 57. Shaw AT, Yasothan U, Kirkpatrick P 2011. Crizotinib. Nat Rev Drug Discov

743 10(12):897-898.

744 58. Ottesen EA, Campbell WC 1994. Ivermectin in human medicine. The Journal of antimicrobial chemotherapy 34(2):195-203.

59. Speare R, Durrheim D 2004. Mass treatment with ivermectin: an underutilized public health strategy. Bulletin of the World Health Organization 82(8):562.

748 60. Kigen G, Edwards G 2017. Drug-transporter mediated interactions between

749 anthelminthic and antiretroviral drugs across the Caco-2 cell monolayers. BMC

750 Pharmacology and Toxicology 18(1):20.

751 61. Guzzo CA, Furtek CI, Porras AG, Chen C, Tipping R, Clineschmidt CM, Sciberras

752 DG, Hsieh JY, Lasseter KC 2002. Safety, tolerability, and pharmacokinetics of escalating

753 high doses of ivermectin in healthy adult subjects. Journal of clinical pharmacology

754 42(10):1122-1133.

755 62. Hayes DJ, van Buuren S, ter Kuile FO, Stasinopoulos DM, Rigby RA, Terlouw DJ

756 2015. Developing regional weight-for-age growth references for malaria-endemic countries

757 to optimize age-based dosing of antimalarials. Bulletin of the World Health Organization

758 93(2):74-83.

759 63. Yu G, Yan G, Zhang N, Zhong D, Wang Y, He Z, Yan Z, Fu W, Yang F, Chen B

760 2013. The Anopheles community and the role of Anopheles minimus on malaria transmission 761 on the China-Myanmar border. Parasites \& Vectors 6(1):264.

762 64. Duke BOL, Zea-Flores G, Castro J, Cupp EW, Muñoz B 1990. Effects of Multiple

763 Monthly Doses of Ivermectin on Adult Onchocerca volvulus. The American Journal of

764 Tropical Medicine and Hygiene 43(6):657-664.

765 65. Chavasse DC, Post RJ, Lemoh PA, Whitworth JA 1992. The effect of repeated doses

766 of ivermectin on adult female Onchocerca volvulus in Sierra Leone. Trop Med Parasitol

767 43(4):256-262.

768 66. Ismail MM, Weil GJ, Jayasinghe KSA, Premaratne UN, Abeyewickreme W,

769 Rajaratnam HN, Sheriff MHR, Perera CS, Dissanaike AS 1996. Prolonged clearance of

770

771 or diethylcarbamazine. Transactions of the Royal Society of Tropical Medicine and Hygiene 90(6):684-688.

67. Campbell WC. 2012. Ivermectin and Abamectin. ed.: Springer.

68. Valadas E, Gomes A, Sutre A, Brilha S, Wete A, Hanscheid T, Antunes F 2013.

Tuberculosis with malaria or HIV co-infection in a large hospital in Luanda, Angola. Journal of infection in developing countries 7(3):269-272.

69. Nyamogoba HD, Mbuthia G, Mining S, Kikuvi G, Biegon R, Mpoke S, Menya D, Waiyaki PG 2012. HIV co-infection with tuberculous and non-tuberculous mycobacteria in western Kenya: challenges in the diagnosis and management. African health sciences 12(3):305-311.

70. Tshikuka Mulumba JG, Atua Matindii B, Kilauzi AL, Mengema B, Mafuta J, Eloko Eya Matangelo G, Mukongo Bulaimu-Lukeba A, Jerry IL 2012. Severity of outcomes associated to types of HIV coinfection with TB and malaria in a setting where the three 784 pandemics overlap. Journal of community health 37(6):1234-1238. 
785 71. Klotz U, Ogbuokiri JE, Okonkwo PO 1990. Ivermectin binds avidly to plasma 786 proteins. European journal of clinical pharmacology 39(6):607-608.

787 72. Crump A 2017. Ivermectin: enigmatic multifaceted 'wonder'drug continues to 788 surprise and exceed expectations. The Journal of Antibiotics 70(5):495-505.

789 73. Campbell W 1985. Ivermectin: an update. Parasitology Today 1(1):10-16.

$79074 . \quad$ DrugBank. Ivermectin. ed.

791 75. Borrmann S, Sallas WM, Machevo S, Gonzalez R, Bjorkman A, Martensson A, 792 Hamel M, Juma E, Peshu J, Ogutu B, Djimde A, D'Alessandro U, Marrast AC, Lefevre G, 793 Kern SE 2010. The effect of food consumption on lumefantrine bioavailability in African 794 children receiving artemether-lumefantrine crushed or dispersible tablets (Coartem) for acute 795 uncomplicated Plasmodium falciparum malaria. Trop Med Int Health 15(4):434-441. 796 76. Ezzet F, van Vugt M, Nosten F, Looareesuwan S, White NJ 2000. Pharmacokinetics 797 and pharmacodynamics of lumefantrine (benflumetol) in acute falciparum malaria. 798 Antimicrob Agents Chemother 44(3):697-704.

799

800 


\section{LIST OF FIGURES}

\section{Figure 1: PBPK workflow model}

803 A 6-step workflow model was implemented. Clinical studies utilised for Step 1 ivermectin 804 compound model development and validation are listed in the figure and fully described in 805 Section 2.1.

806

807

Figure 2: The simulated plasma concentration-time profile of ivermectin in adults

808 Ivermectin was dosed based on the reported clinical studies (see Methods section for details) 809 to healthy volunteer adults. Mean observed plasma concentrations are represented by the 810 open circles, with error bars indicating standard deviations on either the reported 811 concentrations (vertical) or reported $t_{\max }$ (horizontal). Solid lines represent predicted mean 812 plasma concentration with dashed lines indicating $5^{\text {th }}$ and $95^{\text {th }}$ percentiles. For the study by 813 Na-Bangchang et al. (2006), red circles indicate data extracted from complete plasma 814 concentrations profile 'lines' for individual subjects rather than discrete time-points.

Figure 3: The simulated impact of dose escalation on ivermectin plasma concentrationtime profiles in healthy volunteer adult subjects

Ivermectin was dosed as: (A) single oral doses of $0.15-0.60 \mathrm{mg} / \mathrm{kg}$; (B) a single $2 \mathrm{mg} / \mathrm{kg}$ oral dose; (C) a single daily oral dose of $0.15-0.60 \mathrm{mg} / \mathrm{kg}$ for three days; (D) twice daily 0.6 $\mathrm{mg} / \mathrm{kg}$ oral dose for three days; (E) once daily oral dose of $0.60 \mathrm{mg} / \mathrm{kg}$ for five days; $(\mathrm{F}$ ) twice daily oral doses of $0.60 \mathrm{mg} / \mathrm{kg}$ for five days. For all simulations, 100 subjects were simulated with age ranges of 20-50 years. Solid lines represent predicted mean plasma concentrations with dashed lines indicated $5^{\text {th }}$ and $95^{\text {th }}$ percentiles of the lowest and highest doses, where relevant. The dashed horizontal lines indicated the proposed therapeutic window based on the reported LC50 of $16 \mathrm{ng} / \mathrm{mL}$ (lower line) and upper (maximum) concentration simulated from the 2-mg single dose study $(435.20 \mathrm{ng} / \mathrm{mL})$. 
Figure 4: The simulated impact of dose escalation on ivermectin plasma concentrationtime profiles in healthy volunteer paediatric subjects

832

Ivermectin was dosed as (A) single oral doses of $0.15-0.60 \mathrm{mg} / \mathrm{kg}$; (B) a single $2 \mathrm{mg} / \mathrm{kg}$ oral dose; (C) single daily oral doses of $0.15-0.60 \mathrm{mg} / \mathrm{kg}$ for three days; (D) twice daily oral doses of $0.60 \mathrm{mg} / \mathrm{kg}$ for three days; (E) daily oral doses of $0.60 \mathrm{mg} / \mathrm{kg}$ for 5 days; (F) twice daily oral doses of $0.60 \mathrm{mg} / \mathrm{kg}$ for 5 days. For all simulations 100 subjects were simulated with age ranges of 3-5 years. Solid lines represent predicted mean plasma concentrations with dashed lines indicated $5^{\text {th }}$ and $95^{\text {th }}$ percentiles of the lowest and highest doses, where relevant. The dashed horizontal lines indicated the proposed therapeutic window based on the reported LC50 of $16 \mathrm{ng} / \mathrm{mL}$ (lower line) and upper (maximum) concentration simulated from the 2-mg single dose study $(516.91 \mathrm{ng} / \mathrm{mL})$.

Figure 5: The simulated impact of an efavirenz-mediated drug-drug interaction on ivermectin plasma concentration-time profiles in healthy volunteer adult subjects

Efavirenz was dosed as single daily $600 \mathrm{mg}$ oral doses throughout the simulation duration with ivermectin dosed on day 13 onwards, under increasing doses from $0.15 \mathrm{mg} / \mathrm{kg}$ to 2 $\mathrm{mg} / \mathrm{kg}$ as: (A) once daily doses; (B) $1 \mathrm{mg} / \mathrm{kg}$ and $2 \mathrm{mg} / \mathrm{kg}$ as twice daily doses for three days; (C) $1 \mathrm{mg} / \mathrm{kg}$ and $2 \mathrm{mg} / \mathrm{kg}$ as twice daily doses for five days. For all simulations 100 subjects were simulated with data representing ivermectin plasma concentration profiles in the presence of efavirenz. Solid lines represent predicted mean plasma concentrations with shaded areas indicating $5^{\text {th }}$ and $95^{\text {th }}$ percentiles of the lowest and highest doses respectively.

The dashed horizontal lines indicated the proposed therapeutic window based on the reported LC50 of $16 \mathrm{ng} / \mathrm{mL}$ (lower line) and upper (maximum) concentration simulated from the 2-mg single dose study (435.20 ng/mL).

854

Figure 6: The simulated impact of an efavirenz-mediated drug-drug interaction on ivermectin plasma concentration-time profiles in healthy volunteer paediatric subjects

857 Efavirenz was dosed as single daily $250 \mathrm{mg}(15-20 \mathrm{~kg})$ or $300 \mathrm{mg}(20-25 \mathrm{~kg})$ oral doses 858 throughout the simulation duration with ivermectin dosed on day 13 onwards under 859 increasing doses from $0.60 \mathrm{mg} / \mathrm{kg}$ to $2 \mathrm{mg} / \mathrm{kg}$ as: (A) once daily doses; (B) $1 \mathrm{mg} / \mathrm{kg}$ and 2 860 $\mathrm{mg} / \mathrm{kg}$ as twice daily doses for three days; (C) $1 \mathrm{mg} / \mathrm{kg}$ and $2 \mathrm{mg} / \mathrm{kg}$ as twice daily doses for 
861 five days. For all simulations, 100 subjects were simulated with data representing ivermectin

862 plasma concentration profiles in the presence of efavirenz. Data for both the $250 \mathrm{mg}$ and 300

$863 \mathrm{mg}$ efavirenz dose were pooled, and the mean presented, with simulations containing at least 86450 subjects within each dosing band. Solid lines represent predicted mean plasma 865 concentrations with shaded regions indicating $5^{\text {th }}$ and $95^{\text {th }}$ percentiles of the lowest and 866 highest doses respectively. The dashed horizontal lines indicated the proposed therapeutic 867 window based on the reported LC50 of $16 \mathrm{ng} / \mathrm{mL}$ (lower line) and upper (maximum) 868 concentration simulated from the 2-mg single dose study $(516.91 \mathrm{ng} / \mathrm{mL})$.

869

870 Figure 7: Simulated ivermectin plasma concentration in adult and paediatric malaria 871 population group

872 Ivermectin was dosed at $0.60 \mathrm{mg} / \mathrm{kg}$ or $1 \mathrm{mg} / \mathrm{kg}$ to adults (20-50 years) and paediatrics (3-5 873 years) under 3-day dosing (black and red) or 5-day dosing (green). The healthy volunteer 874 population group (Caucasian) was used as a default population group with the Thailand 875 population group created with appropriate age-weight distributions and changes in blood 876 biochemistry to mimic a malaria population group. For all simulations, 100 subjects were 877 simulated. Solid lines represent predicted mean plasma concentrations with shaded regions 878 indicating $5^{\text {th }}$ and $95^{\text {th }}$ percentiles of the Thailand malaria and Caucasian populations, 879 respectively. The dashed horizontal lines indicated the proposed therapeutic window based on 880 the reported LC50 of $16 \mathrm{ng} / \mathrm{mL}$ (lower line) and upper (maximum) concentration simulated 881 from the 2-mg single dose study. 


\section{LIST OF TABLES}

Table 1. Final optimised ivermectin parameters for multi-dose simulations

\begin{tabular}{|c|c|c|}
\hline Parameters & Value & Notes \\
\hline Compound type & Neutral & \\
\hline Molecular weight (g/mol) & $875.1^{1}$ & \\
\hline $\log P$ & $5.8^{2}$ & \\
\hline fu & $0.068^{3}$ & \\
\hline pKa 1 & - & \\
\hline $\mathrm{pKa} 2$ & - & \\
\hline $\mathrm{B} / \mathrm{P}$ & 3.62 & $\begin{array}{l}\text { Predicted by Simcyp } \\
\text { Prediction Toolbox }\end{array}$ \\
\hline Vss (L/kg) & 1.34 & Final optimised using a \\
\hline $\mathrm{SAC}(\mathrm{L} / \mathrm{kg})$ & 0.179 & minimal PBPK model \\
\hline $\mathrm{k}_{\text {in }}\left(\mathrm{h}^{-1}\right)$ & 0.1751 & with a SAC ${ }^{\text {a }}$ \\
\hline $\mathrm{k}_{\text {out }}\left(\mathrm{h}^{-1}\right)$ & 0.0336 & \\
\hline Papp $\left(\times 10^{-6} \mathrm{~cm} / \mathrm{s}\right)$ & $7.6^{4}$ & \\
\hline $\mathrm{CLint}_{\mathrm{P} \text {-glycoprotein }}(\mu \mathrm{L} / \mathrm{min})$ & $2.5^{\mathrm{b}}$ & \\
\hline RAF & $0.1^{\mathrm{b}}$ & \\
\hline $\mathrm{k}_{\mathrm{a}}\left(\mathrm{h}^{-1}\right)$ & 0.38 & Estimated from Peff \\
\hline fa & 0.69 & Estimated from Peff \\
\hline $\mathrm{CL}_{\mathrm{po}}(\mathrm{L} / \mathrm{h})$ & $21.25^{\mathrm{c}}$ & Mean from literature \\
\hline $\mathrm{CLint}_{3 \mathrm{~A} 4}(\mu \mathrm{L} / \mathrm{min} / \mathrm{pmol})$ & $0.28^{\mathrm{c}}$ & Final optimised \\
\hline Absorption model & ADAM & \\
\hline Distribution model & Minimal & \\
\hline
\end{tabular}

a Parameter estimated using a minimal PBPK model with a single adjusting compartment (SAC). ${ }^{b}$ The contribution of active efflux to ivermectin intestinal absorption was assumed to be similar to that of the reported value for digoxin ${ }^{5}$, with RAF empirically optimised through a sensitivity analysis (see supplementary materials). ${ }^{\mathrm{c}}$ CLint $_{\text {CYP }}$ was based on a retrograde calculation, described in Step 1, with fa fixed at 0.56 and $F_{G}$ assumed $=1$. Final estimates were obtained through parameter estimation assuming an fmcyp of 1 for CYP3A4. 
Log P: octanol/water partition coefficient; fu: unbound fraction; B/P: blood-to-plasma ratio; Vss: steady state volume of distribution; $\mathrm{k}_{\mathrm{a}}$ : absorption rate constant; fa: fraction dose absorbed; $\mathrm{CL}_{\mathrm{po}}$ : oral clearance; CLint: in vitro intrinsic clearance for active efflux (Pglycoprotein) or metabolism $(3 \mathrm{~A} 4) ; \mathrm{F}_{\mathrm{G}}$ : fraction of drug escaping the gut enterocyte intact;

RAF: relative activity factor. 
Table 2: Summary of predicted and observed pharmacokinetic parameters of ivermectin used in the validation

\begin{tabular}{|c|c|c|c|c|c|c|c|}
\hline \multirow{2}{*}{$\begin{array}{c}\text { Study } \\
\text { Name and Dose }\end{array}$} & & \multicolumn{2}{|c|}{$\mathrm{C}_{\max }(\mathrm{ng} / \mathrm{mL})$} & \multicolumn{2}{|c|}{$\mathrm{t}_{\max }(\mathrm{h})$} & \multicolumn{2}{|c|}{$\mathrm{AUC}_{0 \text {-inf }}$ or $\mathrm{AUC}_{0 \text {-time }}(\mathrm{ng} / \mathrm{mL} \cdot \mathrm{h})$} \\
\hline & & Predicted & Observed & Predicted & Observed & Predicted & Observed \\
\hline \multirow{2}{*}{ Guzzo: $30 \mathrm{mg}^{6}$} & Day 1 & $77.82 \pm 31.12$ & $84.8 \pm 42.7$ & $3.52 \pm 0.4$ & $4.3 \pm 1$ & $1629.23 \pm 650.58$ & $1724.3 \pm 830.5$ \\
\hline & Day 7 & $99.85 \pm 58.25$ & $87.0 \pm 42.2$ & $3.79 \pm 1.2$ & $4.2 \pm 0.9$ & $3239.82 \pm 1356.66$ & $2819.4 \pm 1691.2$ \\
\hline \multirow{2}{*}{ Guzzo: $60 \mathrm{mg}^{6}$} & Day 1 & $114.23 \pm 102.99$ & $165.2 \pm 95.6$ & $3.11 \pm 0.8$ & $3.6 \pm 0.9$ & $2429.63 \pm 1311.74$ & $2984 \pm 1530.1$ \\
\hline & Day 7 & $162.87 \pm 143.13$ & $186.2 \pm 130.8$ & $3.40 \pm 1.2$ & $4.0 \pm 1.1$ & $6187.15 \pm 3982.52$ & $6061.7 \pm 4243.7$ \\
\hline Guzzo: 90 mg ${ }^{6}$ & Single & $151.63 \pm 95.26$ & $158.1 \pm 87.6$ & $4.11 \pm 0.85$ & $4.9 \pm 1.8$ & $3814.24 \pm 1324.07$ & $2910.2 \pm 1801.9$ \\
\hline Guzzo: 120 mg ${ }^{6}$ & Single & $171.33 \pm 112.28$ & $247.8 \pm 158.9$ & $4.18 \pm 0.89$ & $4.2 \pm 0.9$ & $5124.61 \pm 1498.92$ & $4547.7 \pm 2402.9$ \\
\hline Edwards: $12 \mathrm{mg}^{7}$ & Single & $40.29 \pm 13.36$ & $46 \pm 20$ & $3.40 \pm 0.35$ & $3.6 \pm 0.7$ & $588.71 \pm 211.19$ & $885 \pm 389$ \\
\hline Baraka: $0.15 \mu \mathrm{g} / \mathrm{kg}^{8}$ & Single & $49.62 \pm 11.36$ & $54.4 \pm 12.2$ & $3.40 \pm 0.31$ & $4.9 \pm 1.5$ & $797.31 \pm 157.33$ & $3180 \pm 1390$ \\
\hline Na-Bangchang: $0.2 \mu \mathrm{g} / \mathrm{kg}^{9}$ & Single & $54.01 \pm 14.51$ & - & $3.70 \pm 0.3$ & - & $1609.22 \pm 578.24$ & - \\
\hline Njoo: $0.15 \mu \mathrm{g} / \mathrm{mL}^{10}$ & Single & $39.94 \pm 9.31$ & - & $3.67 \pm 0.29$ & - & $1229.27 \pm 436.68$ & - \\
\hline Okonkwo: $0.15 \mu \mathrm{g} / \mathrm{mL}^{11}$ & Single & $40.45 \pm 15.62$ & $38.2 \pm 16.15$ & $3.73 \pm 0.58$ & $4.7 \pm 1.49$ & $862.12 \pm 277.27$ & $1545.3 \pm 537.4$ \\
\hline
\end{tabular}

Data represent mean $\pm \mathrm{SD} ; \mathrm{AUC}_{0 \text {-time }}$ calculated for studies by Okonkwo ${ }^{11}$ and Edwards ${ }^{7}$.

$\mathrm{AUC}_{0 \text {-ime: }}$ AUC calculated for the study period only; $\mathrm{AUC}_{0 \text {-inf: }} \mathrm{AUC}$ calculated from the start of the study and extrapolated to infinity. 
Table 3: Simulated pharmacokinetic parameters of ivermectin under dose escalation in healthy adult subjects

\begin{tabular}{|c|c|c|c|c|c|}
\hline Duration & $\begin{array}{c}\text { Dose } \\
(\mathrm{mg} / \mathrm{kg})\end{array}$ & $\begin{array}{c}\mathrm{C}_{\max } \\
(\mathrm{ng} / \mathrm{mL})\end{array}$ & $\begin{array}{l}t_{\max } \\
\text { (h) }\end{array}$ & $\begin{array}{c}\mathrm{AUC}_{\text {final dose-t }} \\
(\mathrm{ng} / \mathrm{mL} . \mathrm{h})\end{array}$ & $\begin{array}{c}\text { Time above LC50 } \\
\text { (h) }\end{array}$ \\
\hline \multirow{4}{*}{ 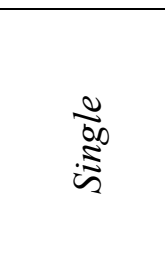 } & 0.15 & $35.47 \pm 8.77$ & $3.41 \pm 0.36$ & $342.58 \pm 89.93$ & 10.4 \\
\hline & 0.3 & $60.52 \pm 15.12$ & $3.49 \pm 0.39$ & $595.75 \pm 164.26$ & 15.8 \\
\hline & 0.6 & $95.86 \pm 31.72$ & $3.55 \pm 0.40$ & $960.29 \pm 335.66$ & 23.2 \\
\hline & 2 & $178.38 \pm 95.98$ & $3.70 \pm 0.42$ & $1779.92 \pm 890.56$ & $>24$ \\
\hline \multirow{4}{*}{$\underset{n}{\stackrel{n}{\sigma}}$} & 0.15 & $41.11 \pm 10.48$ & $3.40 \pm 0.37$ & $1255.36 \pm 522.29$ & 32.2 \\
\hline & 0.3 & $70.80 \pm 20.03$ & $3.47 \pm 0.38$ & $2213.06 \pm 1003.6$ & 86.2 \\
\hline & 0.6 & $113.11 \pm 39.54$ & $3.49 \pm 0.37$ & $3581.99 \pm 1777.58$ & 152.9 \\
\hline & $0.6 \mathrm{BD}$ & $151.51 \pm 66.22$ & $3.29 \pm 0.34$ & $6292.28 \pm 3659.18$ & 178.2 \\
\hline \multirow{2}{*}{ है } & 0.6 & $124.54 \pm 53.19$ & $3.51 \pm 0.37$ & $4543.99 \pm 2513.48$ & 182.3 \\
\hline & $0.6 \mathrm{BD}$ & $174.41 \pm 73.69$ & $3.30 \pm 0.35$ & $8024.87 \pm 4667.20$ & 257.1 \\
\hline
\end{tabular}

Data represents median \pm SD. $\mathrm{n}=100$. For 3- and 5-day simulations, AUC was calculated from the final dosing period to the end of the study period. Time above LC50 (16 ng/mL) was calculated from the median line of each simulation. BD: twice daily. 
Table 4: Simulated pharmacokinetic parameters of ivermectin under dose escalation in healthy paediatric subjects

\begin{tabular}{|c|c|c|c|c|c|}
\hline Duration & $\begin{array}{c}\text { Dose } \\
(\mathrm{mg} / \mathrm{kg})\end{array}$ & $\begin{array}{c}\mathrm{C}_{\max } \\
(\mathrm{ng} / \mathrm{mL})\end{array}$ & $\begin{array}{l}t_{\max } \\
\text { (h) }\end{array}$ & $\begin{array}{c}\mathrm{AUC}_{\text {final dose-t }} \\
(\mathrm{ng} / \mathrm{mL} \cdot \mathrm{h})\end{array}$ & $\begin{array}{c}\text { Time above LC50 } \\
\text { (h) }\end{array}$ \\
\hline \multirow{4}{*}{$\begin{array}{l}\frac{0}{50} \\
: \Sigma\end{array}$} & 0.15 & $42.92 \pm 8.91$ & $3.60 \pm 0.46$ & $394.10 \pm 87.71$ & 10.1 \\
\hline & 0.3 & $81.41 \pm 19.85$ & $3.67 \pm 0.56$ & $763.97 \pm 202.29$ & 14.6 \\
\hline & 0.6 & $145.07 \pm 41.43$ & $3.75 \pm 0.59$ & $1397.10 \pm 444.39$ & 23.9 \\
\hline & 2 & $348.40 \pm 148.95$ & $3.98 \pm 0.75$ & $3423.15 \pm 1506.71$ & $>24$ \\
\hline \multirow{4}{*}{ 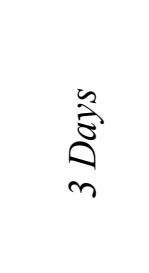 } & 0.15 & $51.02 \pm 10.31$ & $3.58 \pm 0.45$ & $1454.62 \pm 600.10$ & 37.1 \\
\hline & 0.3 & $97.39 \pm 23.83$ & $3.64 \pm 0.52$ & $2858.04 \pm 1252.65$ & 88.1 \\
\hline & 0.6 & $174.85 \pm 51.30$ & $3.72 \pm 0.58$ & $5340.55 \pm 2593.37$ & 151.2 \\
\hline & $0.6 \mathrm{BD}$ & $225.54 \pm 80.71$ & $3.56 \pm 0.54$ & $9109.37 \pm 4790.91$ & 214.5 \\
\hline \multirow{2}{*}{$\hat{a}^{2}$} & 0.6 & $206.22 \pm 62.35$ & $3.58 \pm 0.51$ & $7278.17 \pm 3843.94$ & 234.5 \\
\hline & $0.6 \mathrm{BD}$ & $263.82 \pm 98.72$ & $3.48 \pm 0.48$ & $11712.94 \pm 6438.28$ & 290.1 \\
\hline
\end{tabular}

Data represents median \pm SD. $n=100$. For 3- and 5-day simulations, AUC was calculated from the final dosing period to the end of the study period. Time above LC50 (16 ng/mL) was calculated from the median line of each simulation. BD: twice daily. 
Table 5: Simulated pharmacokinetic parameters of ivermectin in the presence of an efavirenz-mediated drug-drug interactions in healthy adult subjects

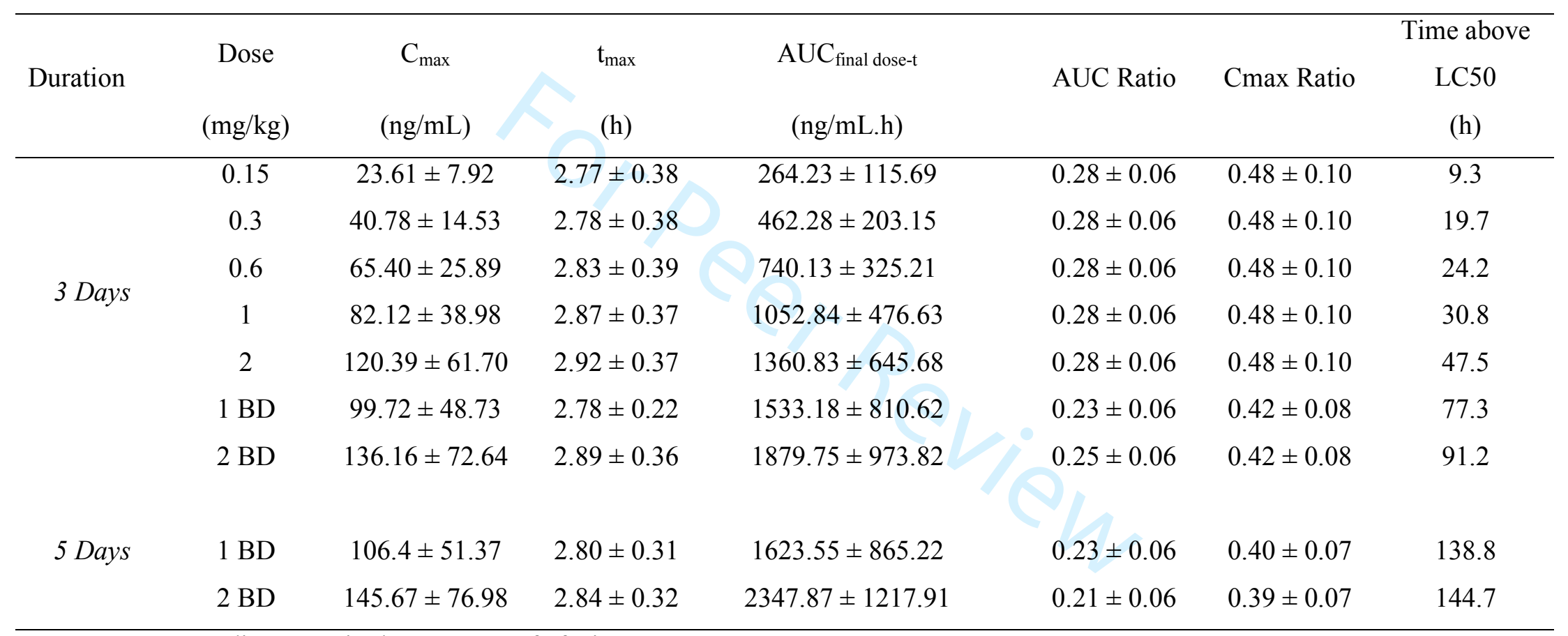

Data represent median \pm SD in the presence of efavirenz. $\mathrm{n}=100$.

For 3- and 5-day simulations, $\mathrm{AUC}_{\text {final dose-t }}$ was calculated from the final dosing period to the end of the study period. Time above LC50 (16 $\mathrm{ng} / \mathrm{mL}$ ) was calculated from the median line of each simulation. 
Table 6: Simulated pharmacokinetic parameters of ivermectin in the presence of an efavirenz-mediated drug-drug interaction in healthy paediatric subjects

\begin{tabular}{|c|c|c|c|c|c|c|c|}
\hline Duration & $\begin{array}{c}\text { Dose } \\
(\mathrm{mg} / \mathrm{kg})\end{array}$ & $\begin{array}{c}\mathrm{C}_{\max } \\
(\mathrm{ng} / \mathrm{mL})\end{array}$ & $\begin{array}{l}t_{\max } \\
\text { (h) }\end{array}$ & $\begin{array}{c}\mathrm{AUC}_{\text {final dose-t }} \\
(\mathrm{ng} / \mathrm{mL} . \mathrm{h})\end{array}$ & AUC Ratio & $\mathrm{C}_{\max }$ Ratio & $\begin{array}{c}\text { Time above } \\
\text { LC50 } \\
\text { (h) }\end{array}$ \\
\hline \multirow{4}{*}{3 Days } & 0.6 & $98.25 \pm 55.72$ & $2.88 \pm 0.47$ & $909.93 \pm 579.05$ & $0.21 \pm 0.10$ & $0.43 \pm 0.13$ & 27.8 \\
\hline & 1 & $159.28 \pm 92.85$ & $3.00 \pm 0.56$ & $1799.69 \pm 987.56$ & $0.21 \pm 0.09$ & $0.43 \pm 0.12$ & 30.9 \\
\hline & 2 & $240.45 \pm 150.97$ & $3.08 \pm 0.59$ & $2225.53 \pm 1503.45$ & $0.21 \pm 0.09$ & $0.43 \pm 0.12$ & 30.9 \\
\hline & $1 \mathrm{BD}$ & $155.06 \pm 90.31$ & $2.98 \pm 0.55$ & $1754.32 \pm 1144.67$ & $0.19 \pm 0.09$ & $0.37 \pm 0.12$ & 81.2 \\
\hline \multirow{3}{*}{5 Days } & $2 \mathrm{BD}$ & $257.42 \pm 162.43$ & $3.07 \pm 0.64$ & $2812.20 \pm 1929.57$ & $0.19 \pm 0.09$ & $0.38 \pm 0.12$ & 104.2 \\
\hline & $1 \mathrm{BD}$ & $176.32 \pm 98.71$ & $3.06 \pm 0.46$ & $2071.25 \pm 1347.96$ & $0.20 \pm 0.09$ & $0.36 \pm 0.12$ & 141.2 \\
\hline & $2 \mathrm{BD}$ & $274.51 \pm 165.31$ & $3.11 \pm 0.58$ & $3114.23 \pm 2006.82$ & $0.20 \pm 0.09$ & $0.36 \pm 0.12$ & 142.1 \\
\hline
\end{tabular}

Data represent median \pm SD in the presence of efavirenz. $n=100$.

For 3- and 5-day simulations, $\mathrm{AUC}_{\text {final dose-t }}$ was calculated from the final dosing period to the end of the study period. Time above LC50 (16 $\mathrm{ng} / \mathrm{mL}$ ) was calculated from the median line of each simulation. BD: twice daily. 


\section{REFERENCES}

1. NCBI. 2017. PubChem Compound Database. ed.

2. DrugBank. Ivermectin. ed.

3. Klotz U, Ogbuokiri JE, Okonkwo PO 1990. Ivermectin binds avidly to plasma proteins. European journal of clinical pharmacology 39(6):607-608.

4. Kigen G, Edwards G 2017. Drug-transporter mediated interactions between anthelminthic and antiretroviral drugs across the Caco-2 cell monolayers. BMC Pharmacology and Toxicology 18(1):20.

5. Schinkel AH, Wagenaar E, van Deemter L, Mol CA, Borst P 1995. Absence of the mdr1a P-Glycoprotein in mice affects tissue distribution and pharmacokinetics of dexamethasone, digoxin, and cyclosporin A. Journal of Clinical Investigation 96(4):16981705 .

6. Guzzo CA, Furtek CI, Porras AG, Chen C, Tipping R, Clineschmidt CM, Sciberras DG, Hsieh JY, Lasseter KC 2002. Safety, tolerability, and pharmacokinetics of escalating high doses of ivermectin in healthy adult subjects. Journal of clinical pharmacology 42(10):1122-1133.

7. Edwards G, Dingsdale A, Helsby N, Orme ML, Breckenridge AM 1988. The relative systemic availability of ivermectin after administration as capsule, tablet, and oral solution. European journal of clinical pharmacology 35(6):681-684.

8. Baraka OZ, Mahmoud BM, Marschke CK, Geary TG, Homeida MMA, Williams JF 1996. Ivermectin distribution in the plasma and tissues of patients infected with Onchocerca volvulus. European journal of clinical pharmacology 50(5):407-410.

9. Na-Bangchang K, Banmairuroi V, Choemung A 2006. High-performance liquid chromatographic method for the determination of ivermectin in plasma. Southeast Asian $\mathrm{J}$ Trop Med Public Health 37(5):848-858.

10. Njoo FL, Beek WMJ, Keukens HJ, Van Wilgenburg H, Oosting J, Stilma JS, Kijlstra A 1995. Ivermectin Detection in Serum of Onchocerciasis Patients: Relationship to Adverse Reactions. The American Journal of Tropical Medicine and Hygiene 52(1):94-97.

11. Okonkwo PO, Ogbuokiri JE, Ofoegbu E, Klotz U 1993. Protein binding and ivermectin estimations in patients with onchocerciasis. Clinical Pharmacology \& Therapeutics 53(4):426-430. 


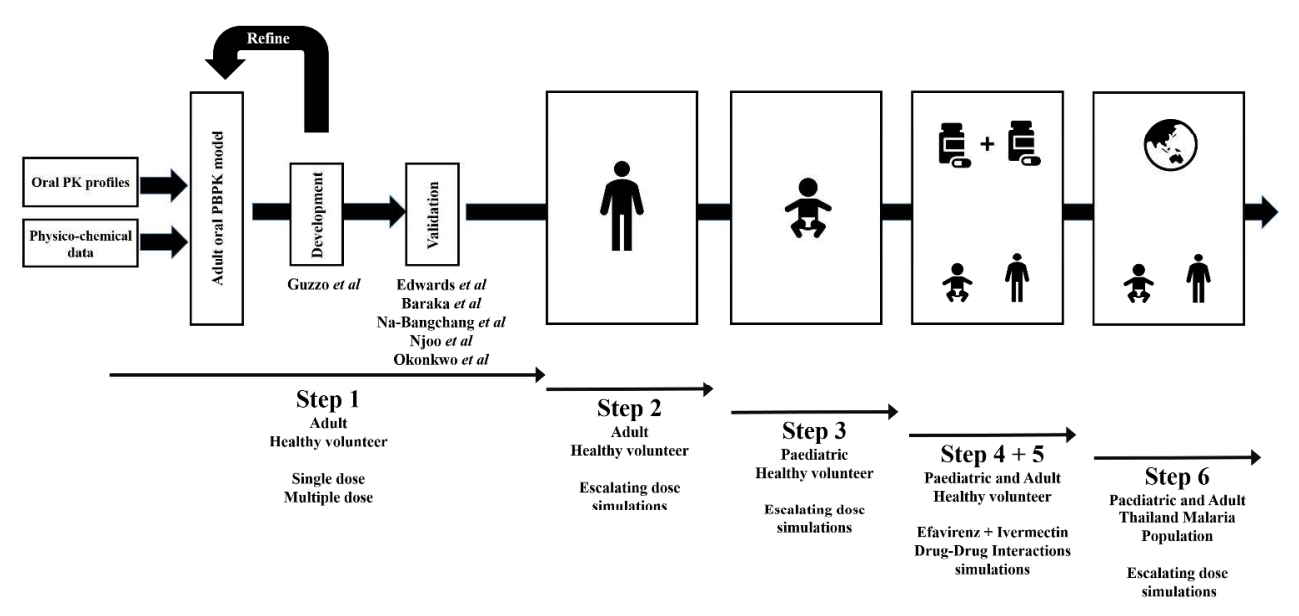

Figure 1

$931 \times 448 \mathrm{~mm}(96 \times 96$ DPI) 


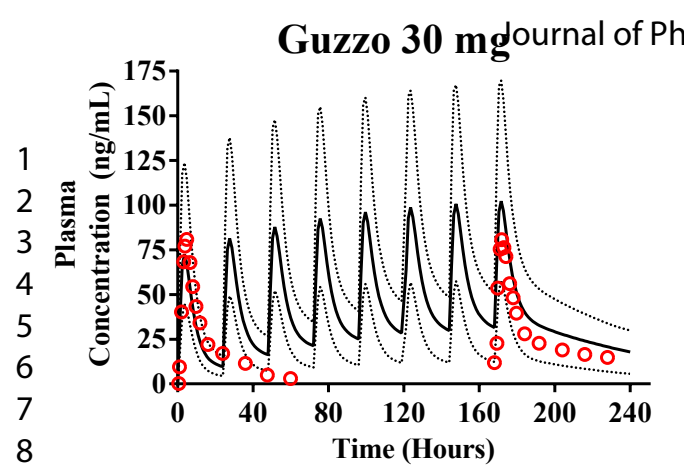

Guzzo 60 mg Page 38 of 48

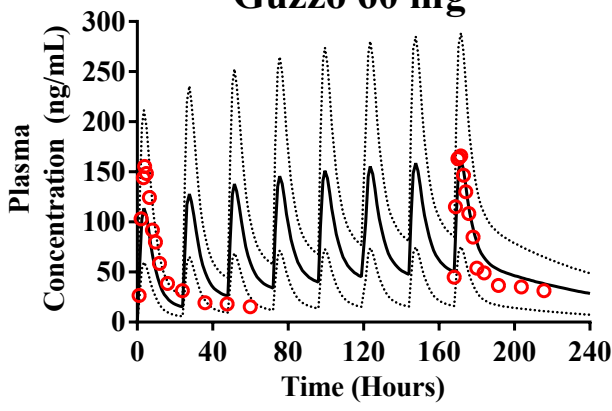

10

11

12

13

14

15 气

$16^{\bar{a}}$

17

18

19

20

21

22

23

24

25

26

$27 \stackrel{\frac{2}{2}}{2}$

28

29

30

31

32

33

34

45

46

47

48

49

50

51

52

53

54

55

56
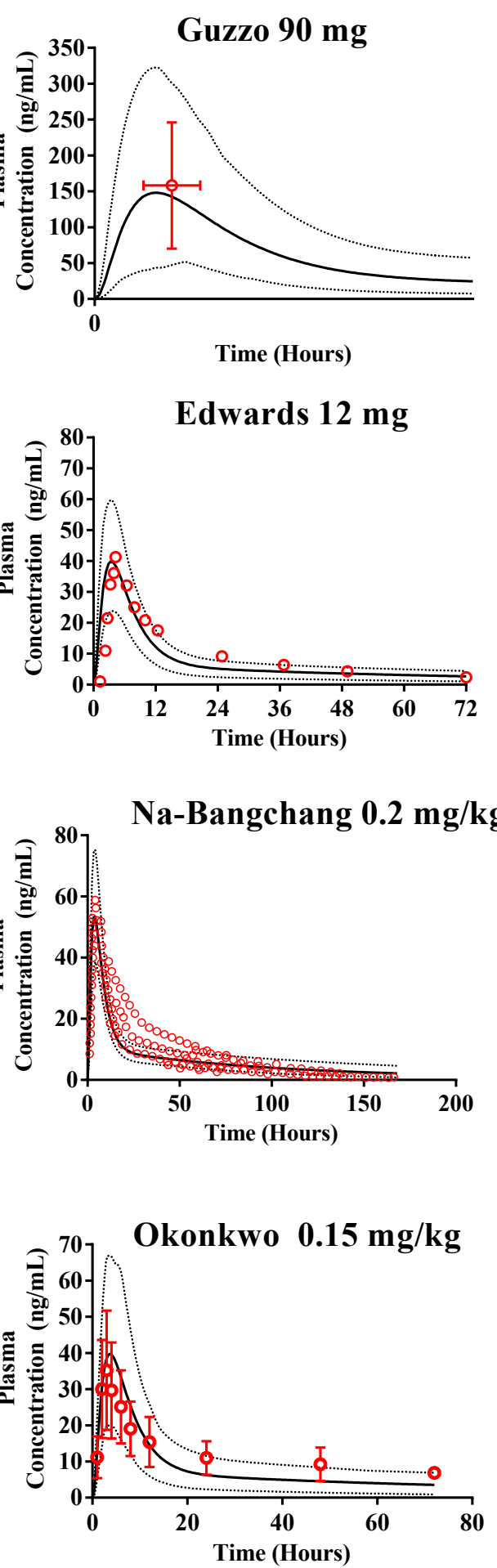
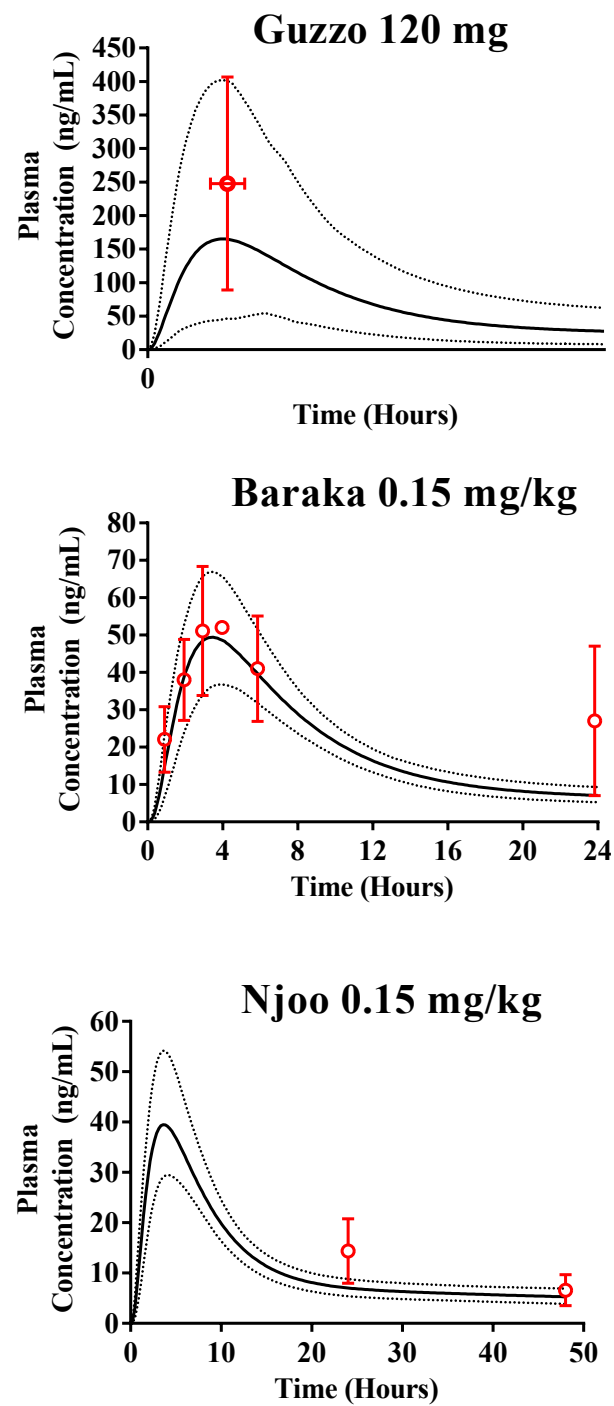

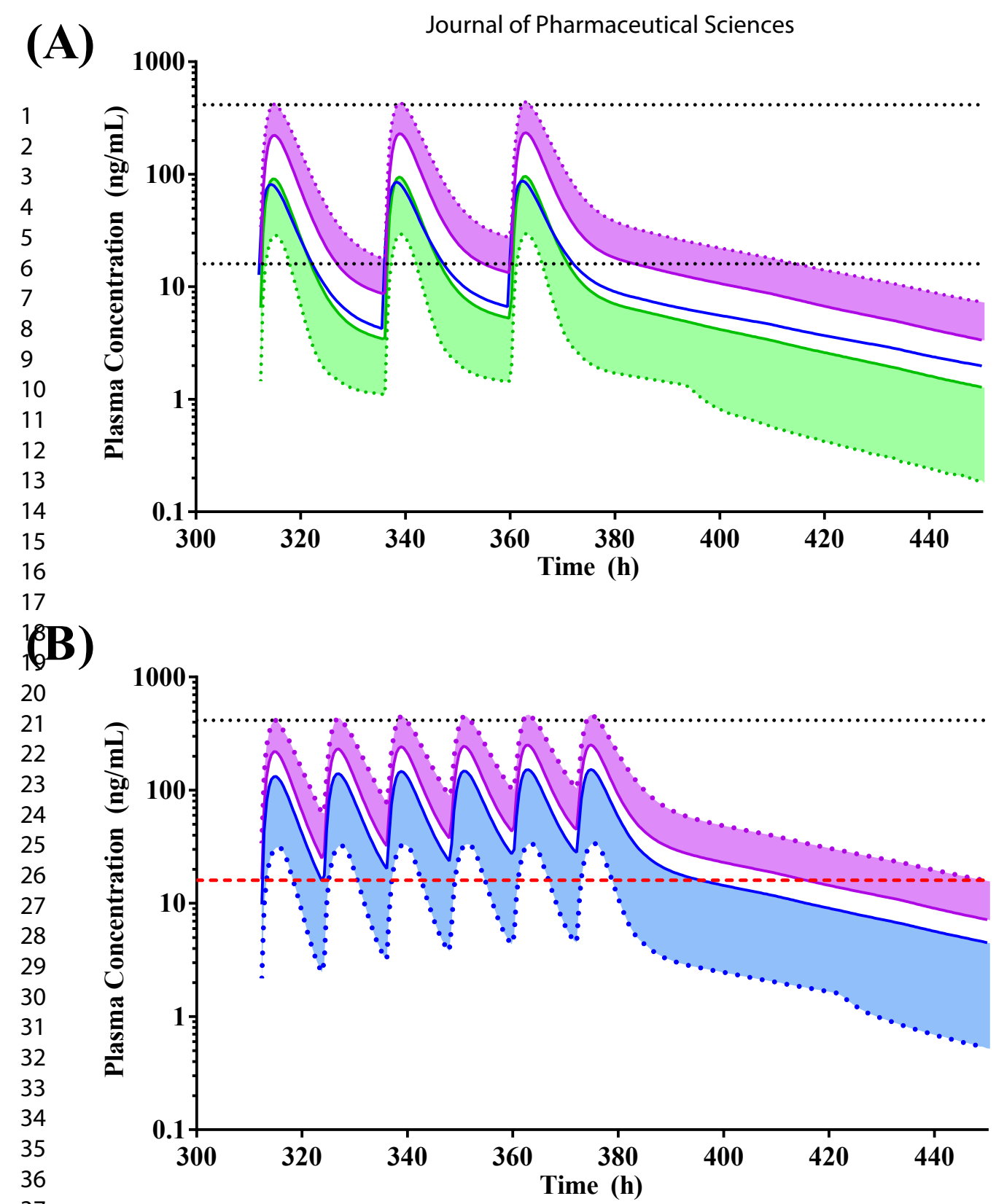

- $2.00 \mathrm{mg} / \mathrm{kg}$

- $1.00 \mathrm{mg} / \mathrm{kg}$

- $0.60 \mathrm{mg} / \mathrm{kg}$

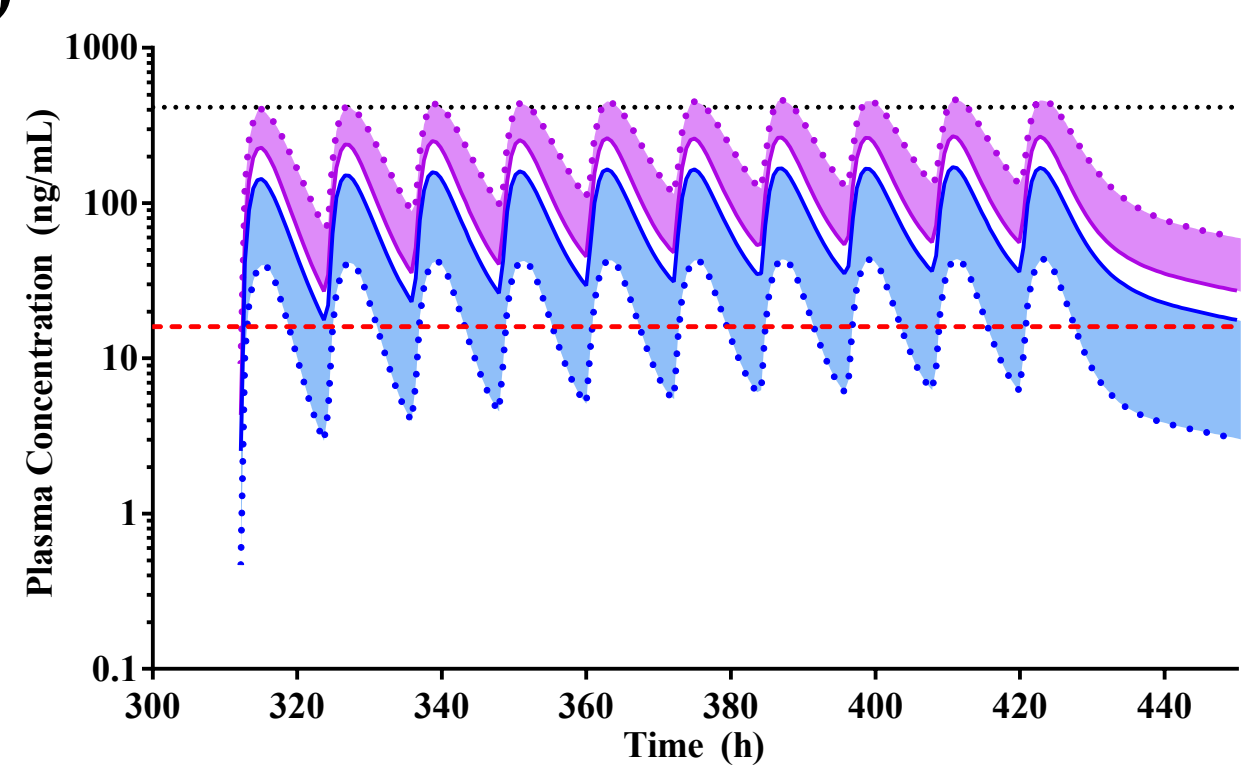




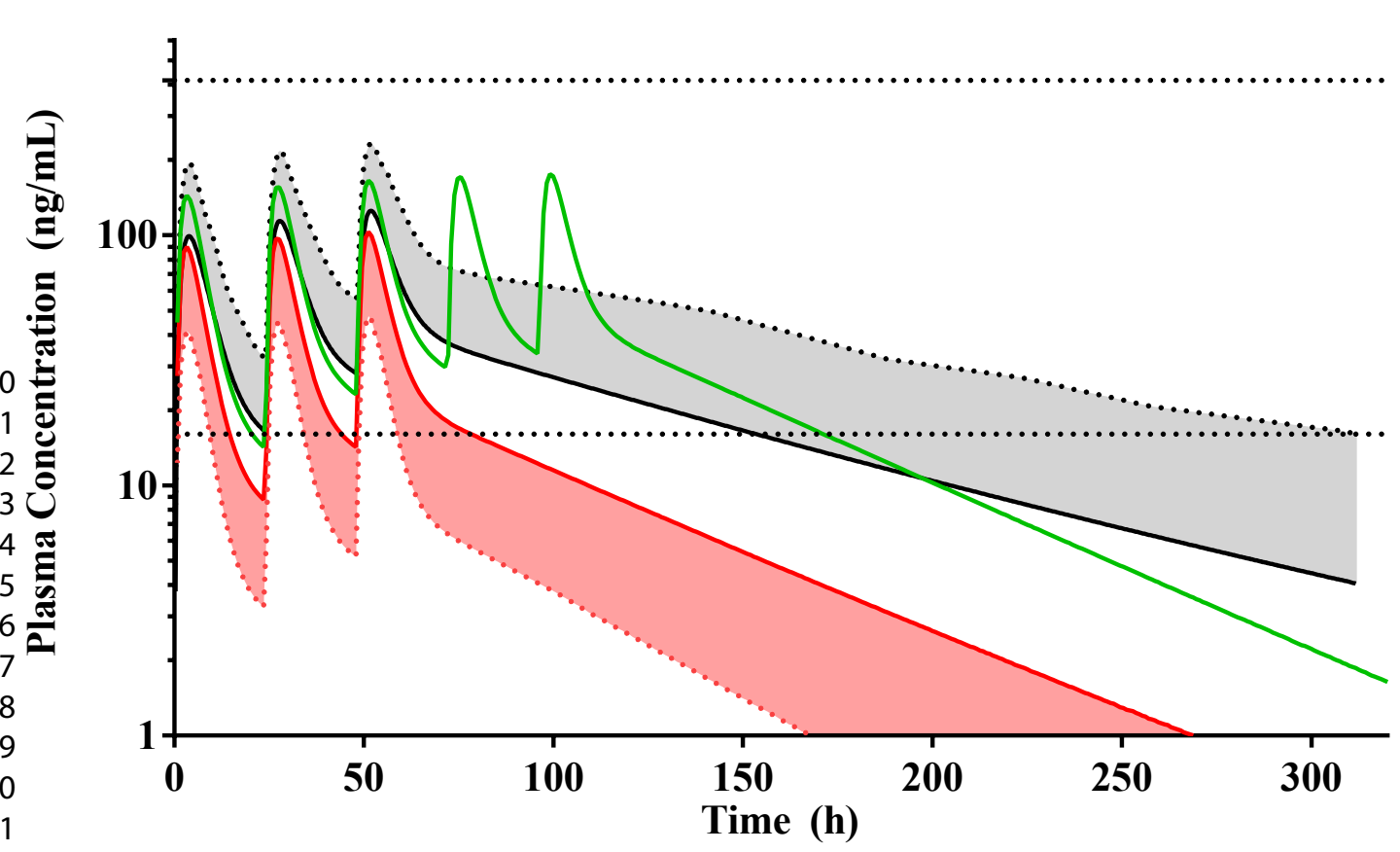

Thailand Malaria Adults (5 day)

_ Thailand Malaria Adults

Caucasian Healthy Adults

\section{(B)}

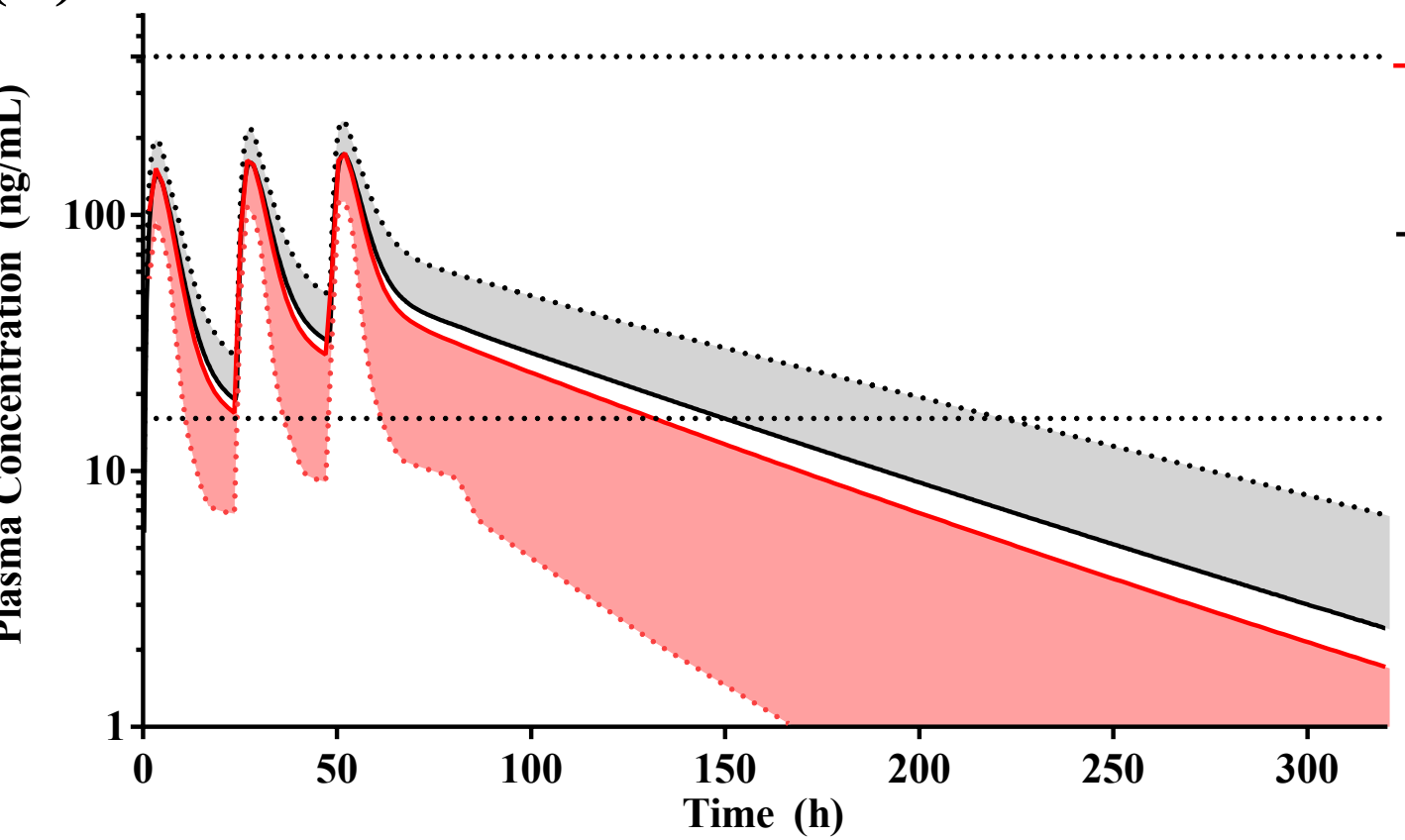

Thailand Malaria Paediatrics

Caucasian Healthy Paediatrics 


\section{Supplementary materials}

\section{Section 1: Model development}

\section{Steady-state volume of distribution (Vss)}

To recover the shape of the distribution and elimination phases of the plasma-concentration time profiles, estimation of the steady-state volume of distribution (Vss) was determined from published clinical data through parameter estimation with observed plasma concentration-time profiles using a weighted least square algorithm with a Nelder-Mead minimisation method, to yield a Vss of $1.343 \mathrm{~L} / \mathrm{kg}$ using a minimal PBPK model. Estimation of the single adjustment compartments (SAC) was $0.179 \mathrm{~L} / \mathrm{kg}$ with inter-compartmental transfer constants $\mathrm{k}_{\text {in }}$ and $\mathrm{k}_{\text {out }}$ of $0.1751 \mathrm{~h}^{-1}$ and $0.0336 \mathrm{~h}^{-1}$.

\section{Metabolic Intrinsic clearance (CLint)}

The ready availability of in-vitro metabolic intrinsic clearance data is limited for ivermectin. However, it has been identified that CYP3A4 is the major metabolic pathway ${ }^{1}$. It was therefore assumed that the major pathway would be attributed to CYP3A4 with an intrinsic clearance (CLint $\left.{ }_{3 \mathrm{~A} 4}\right)$ estimated using the Simcyp retrograde calculator using a fixed $\mathrm{CL}_{\text {oral }}$ of 21.25 L/h, the mean of 5 reported individual $\mathrm{CL}_{\text {oral }}{ }^{2,3}$ (and assuming fa $\sim 0.56{ }^{4}$ ), with CYP3A4 allocated $100 \%$ of the total clearance. The final predicted CLint 3 A4 was 0.28 $\mu \mathrm{L} / \mathrm{min} / \mathrm{pmol}$. Renal clearance has been reported to be negligible ${ }^{5}$ and therefore was not considered within the model.

\section{Passive permeability}

Ivermectin is a low solubility BCS Class II compound, and therefore permeability is thought to be limited. As a result of the lack of a range of published in-vitro Caco-2 permeability measurements, a single published study was utilised which reported an in-vitro apparent permeability $\left(\mathrm{Papp}_{\mathrm{AB}}\right)$ of $7.6 \times 10^{-6} \mathrm{~cm} / \mathrm{s}^{6}$. This was then used in the Simcyp ADAM model to estimate a human jejunum effective permeability (Peff) of $0.88 \times 10^{-4} \mathrm{~cm} / \mathrm{s}$. Subsequently, this was then used to estimate the absorption rate constant $\left(k_{\mathrm{a}}\right)$ and fraction dose absorbed (fa) using the ADAM model resulting in an initial estimate of $0.38 \mathrm{~h}^{-1}$ and 0.69 for $\mathrm{k}_{\mathrm{a}}$ and fa respectively. However, attempts to capture an appropriate $C_{\max }$ and $t_{\max }$ for ivermectin $(\sim 4-6$ hours) ${ }^{2,7,8}$ failed. As ivermectin has also been reported to be a P-glycoprotein substrate ${ }^{6,9}$, 
the contribution of active efflux on limiting intestinal absorption and hence delaying $\mathrm{t}_{\max }$ was modelled by the inclusion of an active efflux component into the model.

Active efflux

Recently Zhou et al (2016) ${ }^{10}$ reported the successful development of a Simcyp model for naloxegol. In the absence of in-vitro reported kinetic efflux parameters, they utilised the Simcyp default digoxin efflux kinetic parameters as a surrogate for the active efflux of naloxegol. This approach resulted in the successful development of a PBPK model for naloxegol.

As ivermectin P-glycoprotein-specific Michaelis-Menten efflux kinetic parameters are absent in the literature, namely the apparent Vmax (maximum velocity) estimated for the carrier system (Jmax) and the Michaelis constant $(\mathrm{km})$, assumptions were made to obtain a reasonable absorption phase profile of ivermectin. We therefore utilised a similar approach as that implemented by Zhou et al (2016) ${ }^{10}$, where the default in-vitro transporter-mediated intrinsic clearance (CLint P-glycoprotein ) value for digoxin $(2.5 \mu \mathrm{L} / \mathrm{min}){ }^{11}$ along with the default Simcyp validated Relative Activity Factor (RAF) (enables in-vitro to in-vivo scaling of transport clearances) were used as a surrogate for ivermectin efflux.

Subsequently we conducted a sensitivity analysis to assess this assumption through exploring the impact of changes in CLint -glycoprotein $(1-12 \mu \mathrm{L} / \mathrm{min})$ and $\mathrm{RAF}(0-1)$ on ivermectin $\mathrm{C}_{\max }$ and $t_{\max }$ (Figure 1), where a $60 \mathrm{mg}$ single oral dose was administered to healthy subjects to mimic the study reported by Guzzo et al. (2002) ${ }^{12}$. The impact of increasing CLint P-glycoprotein on ivermectin $\mathrm{C}_{\max }$ is significant when CLint $\mathrm{P}_{\text {-glycoprotein }}$ and RAF both increase (Figure 1A), with an equally significant increase in the simulated $t_{\max }$ (Figure 1B). An empirical assessment of the sensitivity analysis identified an ivermectin RAF of 0.1 would enable a more appropriate estimate of both the ivermectin $\mathrm{C}_{\max }$ and $\mathrm{t}_{\max }$ when compared to Guzzo et al. (2002) ${ }^{12}$. When this revised RAF was incorporated into simulations, the model was adequately able to capture the reported $\mathrm{C}_{\max }$ and $\mathrm{t}_{\max }$ for the $60 \mathrm{mg}$ single dose, namely 165.2 $\mathrm{ng} / \mathrm{ml} \pm 95.6 \mathrm{ng} / \mathrm{ml}$ and $3.6 \mathrm{~h} \pm 0.9 \mathrm{~h}$.

Further, to ensure these parameter values were appropriate for lower doses, these parameters were also used in validation steps using clinical studies ii-v (See Methods Step 1) at body weight based doses of $0.15 \mathrm{mg} / \mathrm{kg}-0.2 \mathrm{mg} / \mathrm{kg}$ ( $\sim 10-12 \mathrm{mg}$ assuming and average body weight of $75 \mathrm{~kg}$ ) and single doses of $12 \mathrm{mg}$. 
The finalised kinetic parameters describing ivermectin efflux were incorporated into the

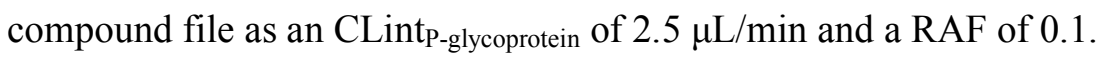
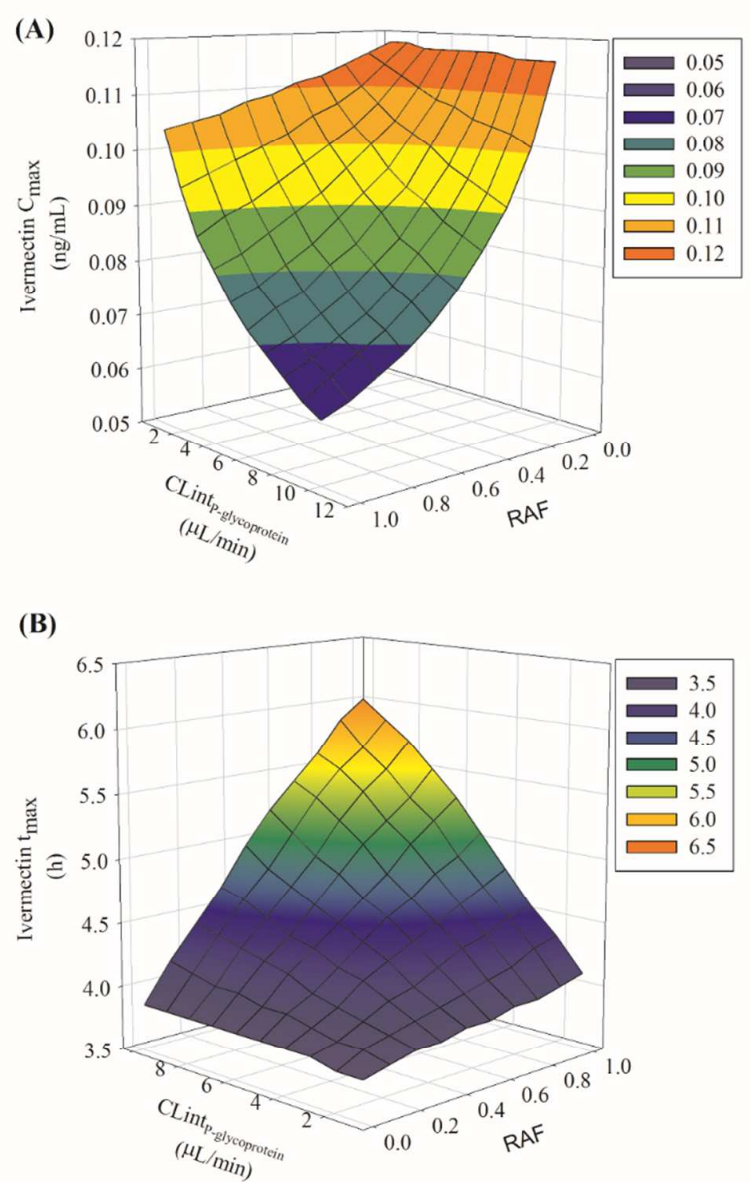

Figure 1: Sensitivity analysis of active efflux and efflux scaling factor on ivermectin $C_{\max }$ and $t_{\text {max }}$.

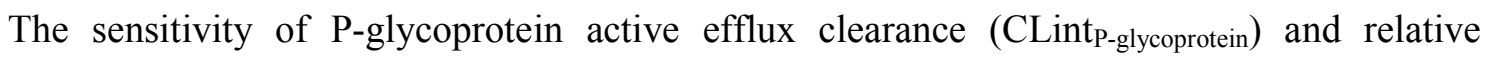
activity factor (RAF) on simulated ivermectin $\mathrm{C}_{\max }$ (A) or $\mathrm{t}_{\max }$ (B). A $60 \mathrm{mg}$ oral dose was administered to a single healthy subject and the sensitivity of $\mathrm{CLint}_{\text {P-glycoprotein }}(1-10 \mu \mathrm{L} / \mathrm{min})$ and $\operatorname{RAF}(0.10-1) \mathrm{C}_{\max }(\mathrm{A})$ or $\mathrm{t}_{\max }(\mathrm{B})$ simulated over 100 simulations.

\section{Solubility}

All dosing was conducted using a solid immediate release dosage form, with dissolution controlled by the intrinsic aqueous solubility with a Simcyp estimate of $0.0013 \mathrm{mg} / \mathrm{mL}$ 
(estimate in literature: $<0.005 \mathrm{mg} / \mathrm{mL}^{13}$ ) assuming a melting point of $155{ }^{\circ} \mathrm{C}$ and using an empirical predictor equation developed by Jain and Yalkowsky ${ }^{14}$.

\section{Section 2: Thailand population group}

The age-weight distribution for male and female Thailand adult and paediatric subjects were extracted from age-weight distribution profiles developed by Hayes et al (2015) ${ }^{15}$ and polynomial/linear equations applied to describe the shape of profiles using an approach described and implemented previously by our group ${ }^{16}$.

The resultant mathematical expression of age-weight distribution are detailed below:

Adult Males

Weight $=33.46+\left(-0.3569 *\right.$ age $\left.^{2}\right)+\left(0.001522^{*}\right.$ age $\left.^{4}\right) /\left(1+\left(-0.00755^{*}\right.\right.$ age $\left.^{2}\right)+\left(2.78 \times 10^{-}\right.$

$5 *$ age $\left.^{4}\right)+\left(-1.07 \times 10^{-9} *\right.$ age $\left.\left.^{6}\right)\right)$

Paediatric Males

Weight $=5.0164+(1.74 *$ age $)$

Adult Females

Weight $=-920.66+(-188.63 *$ age $)+\left(22.48 *\right.$ age $\left.^{1.5}\right)+\left(-0.999 *\right.$ age $\left.^{2}\right)+\left(700.23 *\right.$ age $\left.^{0.5}\right)$

Paediatric Females

Weight $=(5.635+1.121 *$ age $) /(1+-0.0282 *$ age $)$

For paediatric population groups, the age-weight relationship was calculated from 2-6 years of age. In the absence of appropriate age-height distributions, the relationship was assumed to be similar to that described by Simcyp for a healthy volunteer population group.

Blood biochemistry alterations (haematocrit and serum proteins) were also incorporated into the Thailand population group as described previously by our group ${ }^{16}$.

\section{REFERENCES}

1. Zeng Z, Andrew NW, Arison BH, Luffer-Atlas D, Wang RW 1998. Identification of cytochrome P4503A4 as the major enzyme responsible for the metabolism of ivermectin by human liver microsomes. Xenobiotica; the fate of foreign compounds in biological systems 28(3):313-321. 
2. Long Q-C, Ren B, Li S-X 2001. Human pharmacokinetics of orally taking ivermectin. CHINESE JOURNAL OF CLINICAL PHARMACOLOGY 17(3):203-206.

3. Vanapalli S, Chen Y, Ellingrod V, Kitzman D, Lee Y, Hohl R, Fleckenstein L 2003. Orange juice decreases the oral bioavailability of ivermectin in healthy volunteers. Clinical Pharmacology \& Therapeutics 73(2).

4. Takano R, Sugano K, Higashida A, Hayashi Y, Machida M, Aso Y, Yamashita S 2006. Oral Absorption of Poorly Water-Soluble Drugs: Computer Simulation of Fraction Absorbed in Humans from a Miniscale Dissolution Test. Pharmaceutical Research 23(6):1144-1156.

5. Canga AG, Prieto AMS, Liébana MJD, Martínez NF, Vega MS, Vieitez JJG 2008. The pharmacokinetics and interactions of ivermectin in humans - a mini-review. The AAPS journal 10(1):42-46.

6. Kigen G, Edwards G 2017. Drug-transporter mediated interactions between anthelminthic and antiretroviral drugs across the Caco-2 cell monolayers. BMC Pharmacology and Toxicology 18(1):20.

7. Krishna DR, Klotz U 1993. Determination of ivermectin in human plasma by highperformance liquid chromatography. Arzneimittel-Forschung 43(5):609-611.

8. Edwards G, Dingsdale A, Helsby N, Orme ML, Breckenridge AM 1988. The relative systemic availability of ivermectin after administration as capsule, tablet, and oral solution. European journal of clinical pharmacology 35(6):681-684.

9. Schinkel AH, Wagenaar E, van Deemter L, Mol CA, Borst P 1995. Absence of the mdrla P-Glycoprotein in mice affects tissue distribution and pharmacokinetics of dexamethasone, digoxin, and cyclosporin A. Journal of Clinical Investigation 96(4):16981705 .

10. Zhou D, Bui K, Sostek M, Al-Huniti N 2016. Simulation and Prediction of the DrugDrug Interaction Potential of Naloxegol by Physiologically Based Pharmacokinetic Modeling. CPT: Pharmacometrics \& Systems Pharmacology 5(5):250-257.

11. Troutman MD, Thakker DR 2003. Efflux ratio cannot assess P-glycoprotein-mediated attenuation of absorptive transport: asymmetric effect of P-glycoprotein on absorptive and secretory transport across Caco-2 cell monolayers. Pharm Res 20(8):1200-1209.

12. Guzzo CA, Furtek CI, Porras AG, Chen C, Tipping R, Clineschmidt CM, Sciberras DG, Hsieh JY, Lasseter KC 2002. Safety, tolerability, and pharmacokinetics of escalating high doses of ivermectin in healthy adult subjects. Journal of clinical pharmacology 42(10):1122-1133.

13. Williams JB, Nesbitt RU. 1989. Non-aqueous ivermectin formulation with improved antiparasitic activity. ed.: Google Patents.

14. Jain N, Yalkowsky SH 2001. Estimation of the aqueous solubility I: application to organic nonelectrolytes. Journal of pharmaceutical sciences 90(2):234-252.

15. Hayes DJ, van Buuren S, ter Kuile FO, Stasinopoulos DM, Rigby RA, Terlouw DJ 2015. Developing regional weight-for-age growth references for malaria-endemic countries to optimize age-based dosing of antimalarials. Bulletin of the World Health Organization 93(2):74-83.

16. Olafuyi O, Coleman M, Badhan RKS 2017. The application of physiologically based pharmacokinetic modelling to assess the impact of antiretroviral-mediated drug-drug interactions on piperaquine antimalarial therapy during pregnancy. 